\title{
Complex PTSD, affect dysregulation, and borderline personality disorder
}

\author{
Julian D Ford ${ }^{1 *}$ and Christine A Courtois ${ }^{2}$
}

\begin{abstract}
Complex PTSD (CPTSD) was formulated to include, in addition to the core PTSD symptoms, dysregulation in three psychobiological areas: (1) emotion processing, (2) self-organization (including bodily integrity), and (3) relational security. The overlap of diagnostic criteria for CPTSD and borderline personality disorder (BPD) raises questions about the scientific integrity and clinical utility of the CPTSD construct/diagnosis, as well as opportunities to achieve an increasingly nuanced understanding of the role of psychological trauma in BPD. We review clinical and scientific findings regarding comorbidity, clinical phenomenology and neurobiology of BPD, PTSD, and CPTSD, and the role of traumatic victimization (in general and specific to primary caregivers), dissociation, and affect dysregulation. Findings suggest that BPD may involve heterogeneity related to psychological trauma that includes, but extends beyond, comorbidity with PTSD and potentially involves childhood victimization-related dissociation and affect dysregulation consistent with CPTSD. Although BPD and CPTSD overlap substantially, it is unwarranted to conceptualize CPTSD either as a replacement for BPD, or simply as a sub-type of BPD. We conclude with implications for clinical practice and scientific research based on a better differentiated view of CPTSD, BPD and PTSD.
\end{abstract}

Keywords: Borderline personality disorder, Complex PTSD, Dissociation, Affect dysregulation

\section{Review}

Individuals who experience complex (i.e., developmentally adverse interpersonal) trauma (e.g., maltreatment, prolonged family or community violence, torture or exploitation) - especially but not exclusively in formative periods (e.g., early childhood, adolescence)—are at risk not only for posttraumatic stress disorder (PTSD) but also other psychiatric disorders [1], including personality disorders [2-5]. The role of traumatic stress in the etiology and phenomenology of Borderline Personality Disorder (BPD) has received substantial attention [6] because BPD poses particularly difficult clinical challenges consistent with the developmental aberrations associated with developmental trauma [7-9].

Two decades ago, complex PTSD (cPTSD) was defined as a syndrome involving pathological dissociation, emotion dysregulation, somatization, and altered core schemas about the self, relationships, and sustaining beliefs (i.e., morality, spirituality) in the aftermath of

\footnotetext{
* Correspondence: jford@uchc.edu

'University of Connecticut Health Center MC1410, 263 Farmington Avenue, Farmington, CT 06030-1410, USA

Full list of author information is available at the end of the article
}

exposure to traumatic interpersonal victitmization. CPTSD was proposed as an alternative for conceptualizing and treating the symptoms of adults who had suffered prolonged and severe interpersonal trauma, many of whom were diagnosed with BPD [10]. Since then, hundreds of clinical or scientific studies of CPTSD and cognates (e.g., Disorders of Extreme Stress [11,12]; Developmental Trauma Disorder [13,14] have been published. However, the relationship of CPTSD to BPD remains in question, and this question is the focus of the present review.

cPTSD has been both proposed and disputed as a valid and useful [15] clinical syndrome [16,17]. Questions include whether CPTSD is simply a re-packaging or duplication of BPD or whether it provides a rational basis for enhancing the precision of assessment and diagnosis and the range of treatment options for individuals whose BPD symptoms and impairment are caused or exacerbated by the complex traumatic stress reactions [18]. A principal difference between CPTSD and BPD is the assumption in the core definition of cPTSD that its symptoms are sequelae of exposure to traumatic stress, which is not inherent in the definition of BPD. To address these issues, we will review 
clinical and scientific findings regarding: (1) comorbidity and clinical phenomenology of PTSD, cPTSD and BPD; (2) the role of traumatic victimization in BPD and the possibility that cPTSD could represent a sub-type of BPD; (3) the psychobiology of PTSD, cPTSD, and BPD; and, (4) whether a cPTSD conceptualization could clarify the relationship of two hypothesized core mechanisms in BPD, dissociation and affect dysregulation. We conclude with implications for clinical practice and scientific research based on a better differentiated view of PTSD, cPTSD, and BPD.

\section{Prevalence and comorbidity of BPD, PTSD, and CPTSD}

The estimated prevalence in the adult population in the United States of BPD is 6\% [19]. By comparison, across a range of post-industrial nations, the estimated lifetime prevalence of PTSD in adults ranged from 1-10\% [20,21]. cPTSD prevalence estimates have not been reported in community or primary healthcare samples.

PTSD is often noted as a common comorbidity of BPD [22-25]. In nationally representative samples in the United States, approximately 30\% of adults meeting criteria for either PTSD or BPD also met criteria for the other disorder, and closer to $40 \%$ of adults diagnosed with BPD had an episode of PTSD at some point in their lifetime [19]. A 10-year follow-up of adults diagnosed with BPD found that most (85\%) who initially were diagnosed with PTSD continued to meet criteria for BPD but experienced a remission of PTSD [26,27]. However, almost half of remitted PTSD cases experienced a recurrence. Individuals with childhood histories of sexual abuse were least likely to remit on PTSD. More than one in four of the BPD cohort had a new diagnosis of PTSD over the 10-year period, most often following a sexual assault [26,27]. These findings closely parallel those for remission, recurrence, and new cases of substance use disorders (SUD) [26,27], suggesting a need for examination of the course and risk factors for complex comorbid combinations of PTSD, SUD, and BPD. They also speak to the risk of revictimization that has been found to be associated with complex traumatization (especially sexual abuse) in childhood $[28,29]$.

Despite not yet being formally accepted as a psychiatric diagnosis in the Diagnostic and Statistical Manual (IV-TR and 5) (American Psychiatric Association, 2000; 2013), CPTSD also has been reported to frequently co-occur with BPD in both outpatient and inpatient psychiatric and SUD treatment populations [30-36]. As a proxy for cPTSD, several studies have shown that the combination of a history of childhood victimization and DSM-IV PTSD are associated with distinct BPD presentations, including: (1) deficits in cognitive empathy [37] and cognitive affect management [38], (2) suicide attempts [22,39] and lethality [40], (3) non-suicidal self-injury [40,41],
(4) crises leading to hospitalization [25], (5) psychotic symptoms [42], (6) anxious and guilt-prone (rather than disgust- or shame-based) self- concept [43-45], and (7) in approximately $30 \%$ of a sample of patients diagnosed with BPD, obesity [46]. In addition, individuals with a BPD diagnosis or symptoms have been shown to have distinct psychophysiological profiles when PTSD is a comorbidity, including; (1) structural brain abnormalities (i.e., increased gray matter volume) prefrontal cortex areas associated with cognitive control [47], (2) altered brain function (i.e., increased insula and decreased parahippocampal activation in association with increasingly severe dissociation symptoms) [48], (3) reduced amygdala volume [38,49] and altered amygdala metabolism [50], (4) reduced hippocampus volume and increased impulsivity [49], and, (5) neuroendocrine stress hyporeactivity (i.e., cortisol suppression) [51-53].

However, DSM-IV PTSD and child abuse history also have been found to be unrelated to BPD symptomatic or impairment severity [25,41,45,54-58]. Thus, while PTSD may complicate BPD, a more precise formulation of the specific types of trauma-related dysregulation hypothesized to be involved in CPTSD may be necessary in order to account for the role of trauma in BPD.

\section{Clinical phenomenology of BPD, PTSD, and CPTSD}

$\mathrm{BPD}$ and PTSD are relatively distinct with regard to the precise qualitative definitions of their diagnostic features, but nevertheless have substantial potential overlap in their symptom criteria. In the DSM-IV (American Psychiatric Association, 2000) and ICD-10 [10], PTSD symptoms (i.e., dissociative amnesia and flashbacks; emotional numbing; anger) were similar to three BPD features (i.e., transient dissociation, chronic emptiness, and intense anger, respectively). Moreover, the DSM-5's (American Psychiatric Association, 2013) revised PTSD criteria include new symptoms reflecting pervasive negative changes in affect, identity, and behavior which overlap with four other BPD criteria (i.e., identity disturbance, potentially self-damaging impulsivity, self-harm, affective instability). The DSM-5 PTSD diagnostic criteria thus potentially overlap with seven of nine BPD criteria.

The new DSM-5 PTSD symptoms are notable for their relationship to cPTSD. In fact, all of the new or revised PTSD symptoms that potentially overlap with BPD features are cardinal features of cPTSD: affect dysregulation, altered core beliefs about self, reckless or dangerous impulsive behavior, self-harm. In addition, cPTSD involves intense and volatile enmeshment in relationships as a core feature as well as the social detachment and avoidance that are DSM-IV and DSM-5 PTSD criteria [59]:

Proposed ICD-11 complex PTSD is a disorder that requires PTSD symptoms ... but also includes three 
additional features that reflect the impact that trauma can have on systems of self-organization, specifically problems in affective, self-concept, and relational domains. ... The affective domain problems are characterized by emotion dysregulation as evidenced by heightened emotional reactivity, violent outbursts, reckless or self-destructive behavior, or a tendency towards experiencing prolonged dissociative states when under stress. In addition, there may be emotional numbing and a lack of ability to experience pleasure or positive emotions. Self-disturbances are characterized by negative self-concept marked by persistent beliefs about oneself as diminished, defeated or worthless [possibly] accompanied by deep and pervasive feelings of shame or guilt... Interpersonal disturbances are defined by persistent difficulties in sustaining relationships [due to a tendency to either] avoid, deride or have little interest in relationships [or] occasionally experience[ing] close or intense relationships but [having] difficulty maintaining emotional engagement.

The core features of dysphoria in BPD-perceived betrayal and victimization, fragmented sense of self and desire to self-harm, and perceived inability to control extreme affects and impulses [24,60,61]—closely mirror the cPTSD features of relational, self, and affect dysregulation [59], and cPTSD's association with traumatic betrayal [62] and the persistent belief that trauma has created a permanently damaged self and related disorders of the self [10].

However, two BPD diagnostic criteria specifically related to attachment disorganization or insecurity [63] are quite distinct from PTSD in the DSM-5 and from cPTSD: terror of abandonment or rejection, and alternating idealization and devaluation of others. This is consistent with the laboratory research finding that physiological reactivity by individuals with childhood sexual or physical abuse histories who met criteria for BPD was strongest when exposed to scripts highlighting themes of abandonment, while those meeting criteria for PTSD but not BPD had peak physiological reactivity when exposed to scripts of traumatic (e.g., violent, abusive, life-threatening) events [64].

\section{The role of trauma exposure in BPD}

Adults diagnosed with BPD have been shown to be more likely than adults with other psychiatric or personality disorders or no psychopathology to report a history of psychological trauma [5,65-70]. Interpersonal victimization in childhood has been found to be highly prevalent among adults with BPD [71-73] and adolescents with BPD features $[74,75]$. For example, in a sample of adults in psychiatric treatment diagnosed with BPD, $81 \%$ reported histories of interpersonal trauma in childhood, including physical abuse (71\%), sexual abuse (68\%), and witnessing domestic violence (62\%) [76].

Adults with BPD also have been found to be more likely than psychiatric or non-clinical controls to report childhood emotional abuse [77] and neglect or impaired caregivers $[67,69,78,79]$. As a result, traumatic victimization and compromised primary caregiving relationship have been hypothesized to be key etiological contributors to BPD $[7,80,81]$.

Adults with BPD also are at risk for abuse or revictimization in adulthood $[66,67,82]$, and cumulative poly-victimization across the lifespan $[39,66,67,70,82]$. Although severe childhood sexual abuse (i.e., prolonged, violent, multiple perpetrators, physical penetration) was found to be the childhood trauma type most consistently associated with BPD symptoms and impairment [70], neglect likely contributes to, or is a risk factor for BPD [83] because sexual abuse often co-occurs with neglect - and neglect has been shown to be a separate risk factor for BPD [69].

Moreover, BPD has a multi-factorial etiology, and trauma is only one of many potential risks or contributors. Genetics (e.g., temperament) and formative developmental experiences (e.g., maltreatment, caregiving, extra-familial relationships) likely interact in complex ways in BPD etiology [71,80,81,84-87]. The sense of profound emotional pain that was described as "the essential nature" of BPD [88] could be due to traumatic victimization in childhood or adulthood, but could alternately develop in the absence of trauma or victimization when a child experiences disruptions in formative relationships with primary caregiver(s) that lead either actual abandonment or rejection (e.g., neglect; impaired/emotionally unavailable primary caregiver) or perceived abandonment or rejection (e.g., poor fit of child and caregiver due to incompatible temperaments or personalities) $[89,90]$.

Further, BPD is only one of many psychiatric sequelae for which childhood trauma exposure has been demonstrated to be a risk factor. Independent of BPD, childhood trauma exposure places children and adults at risk for mood (e.g., bipolar or major depressive disorder), anxiety (e.g., panic, social phobia), obsessive-compulsive, eating, dissociative, addictive, psychotic, somatoform, and personality disorders, as well as significant safety problems including suicidality, self-harm, impulsivity, aggression, reckless behavior, self-medication, and re-victimization $[1,72]$. When these disorders and severe impairments occur as comorbidities or features of BPD [19,24,60,91-93], these complex cases tend to be particularly chronic, dangerous, and treatment-refractory [8,9,94-100]. Trauma exposure also is highly likely in BPD cases with multiple severe comorbidities, with childhood trauma history prevalence estimates exceeding 90\% [101-103]. Extreme 
BPD-plus-comorbidity cases thus may constitute a CPTSD sub-type of BPD, although whether childhood victimization contributes uniquely to these cases remains to be investigated systematically.

However, it is unlikely that CPTSD occurs only as a BPD sub-type. Although comorbidity frequently occurs in $\mathrm{BPD}$ cases, BPD is a relatively uncommon comorbidity of other psychiatric disorders. Most cases of Axis I and II disorders do not have comorbid BPD: the highest BPD comorbidity rates are $50 \%$ for eating disorders [24], $30-35 \%$ for SUD or bipolar disorder, and $25-50 \%$ for paranoid, avoidant, dependent, and schizotypal personality disorders. BPD comorbidity is typically found in less than $10 \%$ and at most $15-20 \%$ of Axis I or II disorders [19]. Similarly, cPTSD often is accompanied by multiple psychiatric comorbidities, but occurs only rarely as a comorbidity in samples of adults with severe mental illness [32,104], SUD [33], and Axis I disorders including PTSD $[11,12,31,105]$. In cases where either BPD or CPTSD is a comorbidity of another psychiatric disorders, it is likely that there is a history of the types of intra-familial childhood adversity [1,5,79] that have been most consistently found to confer severe impairment related to psychiatric morbidity: "parental mental illness, substance disorder, criminality, family violence, abuse, neglect" [106]. Thus, cPTSD may serve as a sub-type of BPD in which profound developmental trauma causes, or creates a vulnerability to, a range of symptoms and impairments that, in the DSM, results in multiple comorbid diagnoses.

Moreover, severe intra-familial early childhood adversity is a well-established risk factor not just for BPD but for the onset of a wide range of adolescent and adult psychiatric disorders $[106,107]$. Consistent with a cPTSD perspective, across all psychiatric disorders, cases with the heaviest childhood trauma burden also have the most severe psychosocial impairment [106]. Prevalence estimates of trauma exposure for most psychiatric disorders are similar to those cited above for BPD: SUDs (67-90\%) [108], bipolar disorder (50-66\%) [109,110], and other personality disorders $(50-78 \%)$ [102,111]. BPD comorbidity with these disorders is much less prevalent than these estimates of trauma exposure prevalence [19]. If CPTSD was primarily or only a sub-type of BPD, then BPD should be present in all high trauma burden Axis I and II disordersbut this is not the case. Similarly, while psychotic symptoms occur in a substantial subset (i.e., 20-50\%) of BPD cases [42], psychotic disorders rarely (1\%) co-occur with BPD [24] -yet psychotic disorder cases often (50-67\%) involve a history of interpersonal trauma $[101,112]$.

Thus, cPTSD warrants investigation as a potential sub-type of multiple psychiatric disorders, including cases where those disorders do, and do not, have BPD as a comorbidity.
Additionally, there is evidence that childhood trauma exposure and PTSD actually may be more strongly associated with other personality disorder diagnoses or features than with BPD. In adult psychiatric samples, childhood trauma history was more strongly related to paranoid personality disorder than BPD [2] and both PTSD and dissociative disorders have been found to be equally or more often comorbid with avoidant, self-defeating, and passive-aggressive personality disorders as with BPD [113]. An epidemiological study identified two sub-groups representing 25\% of the PTSD cases, one with BPD features (11.4\%) and another with paranoid/obsessive features (13.1\%) [114]. The PTSD sub-group with BPD features was more likely than the other PTSD cases to be drug-seeking due to impaired distress tolerance, consistent with evidence of BPD-PTSD-SUD comorbidity [19]. However, it was the paranoid/obsessive sub-type that was most likely to report a history of sexual trauma, and they also had the earliest onset of PTSD. The paranoid and obsessional styles share a common preoccupation with hypervigilance to perceived threat which is consistent with the PTSD's anxiety and guilt-proneness. That proclivity toward anxiety and guilt also has been shown to be the case when PTSD occurs comorbidly with BPD [43,44], but differs from the self-hatred [115], shame, prolonged and chronic anger and negative affect associated with BPD per se.

Thus, cPTSD appears to involve hypervigilance related to being harmed, while, as noted above, BPD involves extreme sensitivity (which may take the form of hypervigilance) to perceiving oneself as being abandoned or rejected/shamed [63].

\section{Can BPD be distinguished psychobiologically from PTSD and CPTSD?}

As noted above, numerous diagnostic studies have identified a comorbid BPD-PTSD sub-group that differs from BPD alone, both clinically and neurobiologically. BPD has been shown to be associated with smaller hippocampi [38], but a more consistent finding is that reduced hippocampal volume in BPD tends be specific to persons with BPD and comorbid PTSD or childhood maltreatment rather than BPD alone [116]. BPD also is related to reduced amygdala volume-except with comorbid depression [38] and ACC volume [116].

In addition, both BPD diagnosis and childhood sexual abuse history were found to be related to a structural marker for impaired neural network integration (i.e., reduced corpus callosum volume) in a study of women with comorbid BPD and ADHD [43,44], specifically in pathways connecting the right and left hemisphere loci for emotion regulation and self-monitoring, i.e., the ACC [117]. BPD and avoidant personality disorder patients showed dorsal ACC hypo-activation after viewing repeated 
emotionally distressing pictures, as well as smaller increases in insula-amygdala functional connectivity and a lack of habituation in their ratings of the emotional intensity of the images [118]. In BPD this failure of biological and psychological emotion habituation was associated with greater affective instability and reduced insula-ventral ACC functional connectivity. BPD also found to be related to $\mathrm{ACC}$ and orbital $\mathrm{PfC}$ hypo-activation and increased insula and amygdala activation during attempts to distance from distressing emotions [116]. Similarly, ACC hypo-activation occurred when individuals diagnosed with BPD underwent a physical pain induction, although they showed decreased rather than increased amygdala and insula activation, increased dorsolateral PfC activation, and-of note-dissociative analgesia [116]. Amygdala hypo-activation was most pronounced when BPD and PTSD were comorbid, consistent with the dissociative subtype of PTSD [119].

Individuals with BPD and intermittent explosive disorder also showed dorsolateral PfC hypo-activation and elevated orbital PfC and amygdala activation and connectivity in response laboratory tasks eliciting interpersonal frustration [120] and fear [121], similar to the failure of PfC inhibition of amygdala activation found in PTSD and with adults who have child maltreatment histories [122-133]. Whether these functional brain activation patterns are specific to BPD or extend to BPD with childhood interpersonal trauma histories or comorbid PTSD remains to be determined. In BPD, deficits in interpersonal trust, tolerance of aloneness, and recognition of conventional norms of social cooperation/ fairness have been documented and shown to be associated with altered patterns of ACC, temporal lobe, and insula activation [121,134]. These specific forms of interpersonal dysregulation may be distinct to BPD, but whether they are moderated by either childhood maltreatment and PTSD remains to be determined [121]. Thus, unlike the biologically-based emotion dysregulation characterizing fear-related syndromes (e.g., PTSD; avoidant PD), BPD may involve altered brain connectivity associated with emotional instability in response to actual or perceived interpersonal rejection.

The structural and functional brain correlates of CPTSD are less well studied, but there is evidence that individuals with childhood maltreatment histories and CPTSD have reduced hippocampus, ACC, and orbital PfC volumes, with specific correlates of reduced volume in different brain loci: for the ACC, severity of child abuse, PTSD hyperarousal, and BPD; but for the orbital PfC, impulsivity, anger, and BPD [135]. Similar to BPD, CPTSD is associated with a hippocampally-mediated bias toward memory encoding of negative (vs. positive) information [136], but also (in an emotional memory task ) heightened PfC, ACC, amygdala, and hippocampus activation which is the opposite of the diminished PfC inhibition found in studies with either PTSD or BPD [137]. Bryant (personal communication) found similar amygdala and PfC hyper-activation in CPTSD individuals in resting state neuroimaging. These findings suggest that while fear in PTSD and rejection-related distress in BPD may be accompanied by deficient PfC inhibitory activation, in CPTSD they may involve increased-but failed-inhibitory attempts by the PfC.

Physical pain has been found to be problematic in both BPD [88,138] and PTSD (particularly when the latter is comorbid with depression) [139-141], and to potentially be neurobiologically associated with suicide risk, self-injury, and SUD [142,143]. However, BPD and PTSD appear to have distinct pain profiles [144]. BPD often involves pain analgesia consistent with dissociation [7] and self-medication with analgesic medications [94], potentially mediated by a neurobiological substrate (i.e., 2-AG endocannabinoids) specific to BPD (versus PTSD) has been identified [145]. In BPD, physical pain is associated with a complex pattern of heightened co-activation of sensory (e.g., basal ganglia), affective (e.g., amygdala), self-referential (i.e., default mode network [DMN], e.g., precuneus, posterior cinglulate), and executive/ inhibitory (e.g., medial and dorsolateral PfC) brain areas [146], as well as a less integration and connectivity of the PfC with the DMN and an attenuated DMN response [147] associated with dissociation [48].

Interestingly, adult- or childhood-related PTSD also is associated with heightened synchronization of the fear/ salience brain network (centering on the amygdala) and the self-referential DMN (centering on the precuneus and posterior cingulate), and deficient activation of the self-referential DMN $[130,131,148]$ and connectivity between the self-referential DMN and executive networks [149]. However, in PTSD, pain-related impairment, hyperalgesia rather than analgesia, is prominent. PTSD secondary to military combat trauma has been shown to be associated with impairment due to physical pain, particularly among veterans with highly negative self-perceptions [150] and depressive symptoms and illness-related pain coping [140]. PTSD associated with childhood abuse in civilian primary care patients also has been found to involve physical pain impairment (and to mediate that relationship), as well as elevated pain severity and problems with emotion dysregulation [151]. The neurobiology of pain in PTSD is not well understood, although PTSD and chronic physical pain appear to be mutually exacerbating in a bidirectional manner [152], yet PTSD also has been found to be associated with reduced sensitivity to externally induced acute pain [153]. Neuroimaging studies have shown that military veterans with PTSD exhibit increased activation in the hippocampus, insula, and putamen, and decreased 
PfC and amygdala activation in reaction to externallyinduced acute pain [153], while women with PTSD secondary to interpersonal violence showed increased activity in both the insula and PfC during acute pain but reduced insula activation with repeated pain induction [154]. When physical pain was induced following scriptbased recall of traumatic events, PTSD symptom severity was found to be associated with activation in brain areas related to stress-induced analgesia (e.g., caudate, thalamus), and dissociative symptoms were correlated inversely with activation of the putamen and amygdala [155]. Thus, the neurobiology of pain in PTSD is complicated and appears to range from acute analgesia (associated with dissociation) to chronic hyperalgesia (associated with affective distress and hyperarousal).

While preliminary and not directly testing associations with CPTSD, taken together these findings suggest that emotion dysregulation in BPD may involve brain alterations associated with deficient self-awareness, intolerance of interpersonal rejection or abandonment, inability to recover from intense negative affect states, and dissociative analgesia. PTSD secondary to childhood maltreatment, by contrast, appears to involve brain alterations associated with heightened self-awareness of vulnerability, hypervigilance to a wide array of safety threats and related threat appraisals, tolerance of (and possibly habituation to) chronic negative affect states, and dissociative re-experiencing with alternating states of fear/hyperalgesia and detachment/ analgesia. PTSD uniformly also involves persistent fear manifested as physiological hyperarousal due to an explicit or implicit attentional bias toward (i.e., hypervigilance), or avoidance of, actual or perceived threats $[59,156]$.

In the ICD-10 and DSM-IV, hypoarousal also is included in PTSD in the form of dissociative amnesia, emotional numbing, and anhedonia, and the DSM-5 a hypoarousalbased dissociative sub-type [119]. cPTSD adds to the core PTSD fear symptoms three forms of dysregulation which may involve either or both hyperarousal and hypoarousal: (1) emotion processing, (2) self-organization (including bodily integrity), and (3) relational engagement $[33,59,156,157])$.

A common denominator across the newer PTSD features also is central to BPD: under-regulation of extreme negative affect states $[35,36,158,159]$. In both BPD and PTSD secondary to childhood maltreatment, under-regulation of affect are marked by inability to recover from episodes of chronic intense negative affect $[75,121]$ and dissociation [7]. Therefore, investigation of how dissociation and affect dysregulation in BPD and CPTSD have shared or different patterns of brain structure and function, and associated clinical phenomenology, is crucial to determining the nosological and scientific relationship of BPD and CPTSD.
BPD has been shown to involve deficits in social cognition related to dichotomous thinking, distrust, aggressive attributions, and increased attention to, but impaired recognition, understanding, and empathy for, others' emotions, thoughts, and intentions. Alterations in brain structure (e.g., cortical thickness) and activation (in the prefrontal and temporal cortices) associated with BPD social cognitive deficits also have been identified [37,160-166]. Research on social cognition in PTSD is more limited, but one study found that women with BPD were more likely to have empathic deficits if they had comorbid PTSD with severe intrusive re-experiencing and a history of sexual trauma [165]. PTSD by definition involves a numbing of emotion awareness and detachment from interpersonal relationships secondary to an attention bias toward threat $[167,168]$, consistent with evidence that PTSD may have a dampening effect on emotional reactivity in BPD [51,52]. Further study is needed both of the differences in altered social cognition in BPD and PTSD, and of PTSD's effects on social cognition in BPD when the disorders co-occur.

\section{Dissociation in BPD, PTSD, and CPTSD}

Dissociative symptoms are a cardinal feature of the BPD diagnosis, but as transient and not chronic states that occur "during periods of extreme stress ... most frequently in response to real or imagined abandonment" (American Psychiatric Association, 2013, p. 664). Yet, a high proportion of individuals with BPD report clinically significant dissociative symptoms $[7,169]$. Potential neurobiological substrates for dissociation in BPD have been identified, including increased glutamate concentrations in the ACC and impulsivity [170], and increased volume of the precuneus-the component of the self-referential DMN specifically implicated in episodic self-relevant memory [171].

The role played by PTSD or childhood traumatic victimization in dissociation in BPD has not been definitely established. Although limited in generalizability due to originating in a research site specializing in treatment of dissociative identity disorder (DID), a study of adult psychiatric inpatients predominantly (72\%) diagnosed with BPD with a large sub-group diagnosed with DID (46\%) conducted a detailed assessment of retrospectivelyrecalled childhood sexual and physical abuse [172]. Most (82\%) of the DID-diagnosed patients met criteria for BPD, but about half of the BPD-diagnosed patients were not diagnosed with DID. Most of the inpatients (80\%) had childhood exposure to sexual and/or physical abuse, but this was true of all of the comorbid BPD-DID patients and their trauma severity scores (including number of types, perpetrators, and duration of abuse) were 50\% (vs. DID only) to $100 \%$ (vs. BPD only or other psychiatric disorders) higher than other patients'. The findings suggest 
that there may be a BPD sub-type characterized by severe dissociative symptoms, and by correspondingly severe childhood traumatic victimization.

Dissociation was included as a core feature in early formulations of cPTSD [173,174], but its inclusion as a core feature of cPTSD has not been empirically supported [104]. There is psychobiological evidence supporting the existence of a dissociative sub-type of PTSD [30,119,175], particularly among individuals with histories of childhood traumatic victimization [176]. Moreover, dissociative disorders are common comorbidities of PTSD among individuals with histories of childhood traumatic victimization $[177,178]$.

Dissociation thus occurs in a sub-set of individuals with either BPD or PTSD/cPTSD, but whether these sub-groups overlap or are distinct has yet to be investigated. Dissociation could be a common factor linking BPD and CPTSD, or a sub-group with comorbid BPD and CPTSD, but it also could be a comorbidity associated with but independent of both BPD and CPTSD. Post-traumatic dissociation has been conceptualized as an extreme expression or endpoint of affect dysregulation [179], and therefore it may be affect dysregulation more generally rather than dissociation per se that connects (or differentiates) BPD and cPTSD.

\section{Affect dysregulation in CPTSD and BPD}

Affect dysregulation specific to interpersonal stressors, actual or perceived, is a hallmark of BPD. Affect dysregulation in BPD phenomenologically and clinically involves high sensitivity to emotion in social contexts, heightened and labile negative affect, and both a deficit in adaptive and surfeit of maladaptive emotion regulation strategies [180]. Affect dysregulation (specifically, distress intolerance and deficits in adaptive emotion regulation and emotion clarity) were shown to account for the shamebased [181] heightened fear of social rejection in adults diagnosed with BPD [51,52]. Problems with distrust and interpersonal lability and aggression in BPD have been linked to perceptual biases and cognitive deficits related specifically to a tendency toward perceived social exclusion/abandonment [163].

Functionally, affect dysregulation can be divided into under-regulation-difficulties in modulating and recovering from uncontrolled experiencing and expression of extremely intense forms of negative affect (e.g., rage, despair, impulsivity), and over-regulation (i.e., numbing, suppression, or dissociation) of positive and negative affect $[158,159]$. Both over- and under-regulation of affect have been shown to be associated with BPD symptom severity [182], and under-regulation of affect has been shown to be associated with BPD diagnoses as well as to account for the relationship of childhood maltreatment history and chronic negative affect with BPD [183].
However, affect dysregulation is a factor in most if not all psychiatric disorders and not just BPD. For example, BPD diagnosed adults did not evidence a distinct pattern of physiological emotional processing - despite being physiologically activated in response to interpersonal challenge scripts - compared to those diagnosed with obsessive-compulsive disorder [184]. Moreover, affect dysregulation is heterogeneous in its expression within BPD. Cocaine-dependent BDP-diagnosed men, but not women, showed a greater tendency than cocainedependent men not diagnosed with BPD to focus their attention on cocaine-related stimuli after being exposed to trauma-related laboratory cues [185]. The researchers suggested that this may reflect an attempt by men who have comorbid BPD and cocaine-dependence to attempt to reduce emotional distress related to reminders of traumatic experiences. Although BPD-diagnosed women in a clinical sample had more affect regulation problems in general than non-BPD controls, a sub-group with comorbid avoidant personality disorder was found to have particularly severe deficits in tolerating distress and accessing adaptive emotion regulation strategies cognitively and physiologically (i.e., reduced heart rate variability when exposed to a stressor [186]. These findings raise the possibility that affect dysregulation-particularly under-regulation of affect due to impaired adaptive strategies and high levels of distress intolerance-may be a marker for a sub-group among BPD-diagnosed persons distinct from the majority who also struggle with affect dysregulation but tend to be tonically tolerant of distress and intermittently overwhelmed. The deficits in adaptive emotion regulation and problems with impulsivity and avoidance/self-medication characterizing this putative sub-group are consistent with descriptions of cPTSD.

Affect dysregulation thus may constitute a developmental pathway from childhood maltreatment to BPD. Latency/pre-adolescent children with BPD symptoms were found to be characterized by both chronic negative affect and impulsivity/disinhibition, with emotion-regulation deficits partially mediating those relationships [187]. Pre/early adolescent children with histories of emotional abuse were found to be at risk for developing BPD symptoms only if they also had problems with underregulated affect and impulsivity [188]. A study with non-clinical adolescents found that distress intolerance, deficits in adaptive emotion regulation, and impulsivity each was independently associated with BPD symptoms [189].

However, affect dysregulation has been shown to play a major role in most Axis I and Axis II psychiatric disorders $[190,191]$. Therefore, the specificity of affect dysregulation, and its precise nature, in BPD and CPTSD was investigated in a study of adult psychiatric inpatients who met 
criteria for BPD only, BPD with a comorbid somatoform disorder, or a somatoform or other severe Axis I disorder without BPD. Individuals with BPD were more likely than the other patients to have problems with under-regulation of affect $(67 \%$ vs. $25 \%$ of somatoform disorder patients, most of whom also had problems with over-regulation), but one in three BPD participants did not have problems with under-regulation, including $20 \%$ who only had over-regulation problems $[158,159]$. The most common profile for BPD patients (40\%), with or without comorbid Axis I somatoform or other psychiatric disorders, was a combination of under- and over-regulation of affect. A similarly sizable (i.e., 40-50\%) sub-group of individuals with BPD also reported clinically significant dissociation, almost always in combination with affect dysregulation [158,159]. The combined dissociative/dysregulated presentation took three forms, either an excitatory state consistent with PTSD (e.g., trauma memory flashbacks), an inhibitory loss of awareness consistent with dissociative disorders and the dissociative PTSD sub-type (e.g., derealization, depersonalization), or the combined excitatory/underregulated and inhibitory/over-regulated presentation. Over-regulation of affect was more prominent in somatoform disorder than BPD or other Axis I psychiatric disorders [158,159], consistent with evidence linking somatoform disorders with alexithymia [192].

cPTSD was assessed in that psychiatric inpatient study as well $[35,36]$. While most often comorbid with BPD (33\%), cPTSD was not present in two of three BPD cases, and occurred most often when BPD and somatoform disorders were comorbid (38\%). Thus, the combination of positive dissociation with under-regulated affect or negative dissociation with over-regulated affect was likely to best characterize CPTSD - but not BPD per se. BPD also was found to be associated with difficulty in recognizing emotions and distinguishing self-referential beliefs from reality, while anxiety and affective disorders were associated with difficulty in experiencing emotions and somatoform disorders were characterized by a deficit in self-referential beliefs.

These findings suggest that not only are affect dysregulation and dissociation complexly interrelated for different persons with BPD but that, based on clinical phenomenology, cPTSD is likely to extend beyond BPD. cPTSD includes features that reflect both under- and overregulation of affect, positive and negative dissociation, difficulties in both experiencing and recognizing emotions, and both a surfeit and deficit in self-referential beliefs. A sub-set of BPD cases may, for example, represent a sub-type of cPTSD rather than vice versa. In such cases, a combination of traumatic victimization and disrupted primary caregiver attachment relationships might be expected, and this represents a final relevant line of research to review.

\section{The role of maltreatment by primary caregivers in BPD}

Primary caregivers play an essential role in children's development of emotion regulation capacities, and have been hypothesized to contribute to the risk of BPD when they fail to bond and attune emotionally with their child [83] or to protect their child from victimization [193]. However, most children whose primary caregivers are dysregulated or insufficiently protective-or even abusive-do not develop BPD [194]. Maltreatment by primary caregivers is, however, consistently associated with children's emotion dysregulation [195,196]. Therefore, we next consider the clinical and research evidence linking primary caregiver relationships, and specifically maltreatment in those relationships, with BPD.

Emotion regulation is known to be founded on developmental attainments (e.g., emotion self-awareness, empathy, self-control) that are profoundly influenced by interaction with primary caregivers beginning in infancy and extending through childhood [197]. Affect dysregulation in adolescence and adulthood correspondingly has been found to be associated with childhood relationships with primary caregivers who are unresponsive, poorly attuned, or punitive [90]. Consistent with this, individuals with BPD often report childhood histories of primary caregiver neglect, abuse, invalidation, or impairment $[79,83,198]$. In a combined concurrent and retrospective study, young women meeting BPD criteria were particularly likely compared to age-matched women with no psychiatric diagnosis to report feeling unprotected in their relationship with their mother and to have elevated cortisol levels at the outset of a laboratory interaction with their mother [193]. Infants of mothers with BPD also were found to be less attentive and contact-seeking with their mothers, who in turn were found to be less responsive, able to provide structure, satisfied and self-confident [199], and more likely to express fear or disorientation [200] in their interactions with their infant children, compared to mothers with no psychiatric diagnosis.

Although compromised childhood attachment relationships with primary caregivers may be a key factor in the development of BPD, most children with insecure or disorganized attachment relationships and most adults who recall a troubled, insufficiently protective, or even frankly rejecting or severely neglectful relationship with primary caregivers do not develop BPD [81]. It is possible that only explicitly traumatic experiences in relation to primary caregivers account for vulnerability to or the etiology of BPD-in which case the sub-group of individuals with BPD who have experienced traumatic victimization by (or in relation to) a primary caregiver may be better characterized by cPTSD either as a BPD comorbidity or as the primary disorder. Pursuing that question, a study compared psychiatric inpatients diagnosed with BPD to those with severe somatoform or mood/anxiety disorders and found 
that the BPD cases were most likely to report traumatic victimization by a primary caregiver and severe underregulation of affect [35,36]. Moreover, under-regulation of affect partially mediated the relationship between traumatic victimization by a primary caregiver and BPD [201]. A history of traumatic victimization by primary caregiver was reported by most BPD-diagnosed inpatients (75\%), but also was reported by a majority (51\%) of the inpatients with Axis I disorders [35,36].

Consistent with most approaches to psychotherapy for BPD [202], trusted and trustworthy relationships can serve a protective role, reducing the risk of developing BPD characteristics when a child experiences traumatic victimization in primary caregiving relationships. A study with college students found that having valued relationships outside the family in the larger community statistically mediated-and mitigated against-the risk of developing BPD traits associated with a history of exposure to childhood betrayal trauma [203]. These findings suggest that the role of traumatic victimization in the etiology of BPD may be obscured in many fortunate cases where protective relationships mitigate against its adverse effects.

\section{Implications for clinical practice and research}

Findings from this review of clinical and neurobiological research suggest that BPD may involve heterogeneity related to psychological trauma that includes but extends beyond comorbidity with PTSD and potentially involves childhood victimization-related dissociation and affect dysregulation consistent with cPTSD. BPD and CPTSD overlap substantially, but it does not seem warranted to conceptualize cPTSD either as a replacement for BPD nor simply as a sub-type of BPD. Persons with severe childhood traumatic victimization histories are at risk for BPD, PTSD, and CPTSD, but the clinical phenomenology and neurobiology of the three syndromes are distinct: unlike severe PTSD or cPTSD, BPD does not always involve traumatic antecedents but usually involves severe attachment insecurity and disorganization. The implications and unanswered questions raised by these findings will next be discussed.

\section{Assessment}

Clinicians evaluating severely distressed clients with significant trauma histories may find that clearly distinguishing BPD and CPTSD can increase their precision in assessing and formulating treatment plans to address complex forms of affect dysregulation and dissociation which often accompany the trauma-related hypervigilance and dissociative features of PTSD. When abandonment terror is combined with habituation to extreme distress and alternating idealization and devaluation of self and others are prominent, as well as a history of neglect or otherwise compromised childhood relationships with primary caregivers, the careful safety planning and affect identification skills that are hallmarks of efficacious BPD treatment are indicated [202]. On the other hand, when hypervigilance and intrusive re-experiencing centers on fear of trusting self (including one's own bodily reactions, emotions, and thoughts) or others (who are perceived as unreliable but not fundamentally devalued) to recognize and handle threats, and there is a history of abuse or emotional betrayal in primary relationships, the affect modulation and self-reparative skills that are central to efficacious cPTSD treatment are indicated $[204,205]$. If only PTSD is assessed, for example with a severely and chronically polyvictimized client, the evaluation may fail to identify crucial components of affect dysregulation and altered relational- and self-schemas that may shape, amplify or perpetuate intrusive re-experiencing, avoidance, pervasive negative affect states and beliefs, hypervigilance, and dissociation. Although, as noted above, the DSM-5 PTSD criteria have been expanded to include aspects of affect, relational, and self-dysregulation, the emphasis in PTSD remains upon re-experiencing and hypervigilance with dysregulation not a fully delineated as in CPTSD and BPD.

Considered together within a cPTSD framework, PTSD and BPD could provide a phenomenological and nosological understanding of the separate and combined impacts of the survival threat central to PTSD [206] and the invalidation of self that is a core feature of BPD [207]. A cPTSD integration yields a complex formulation that is more than the sum of its parts [208]. For example, a cPTSD perspective could clarify how a client with a history of betrayal trauma [62] may experience dissociative episodes alternating with rage and impulsive/reckless behavior. In such a case, if relational stressors elicit extreme distress or alternating devaluing and idealization in current relationships related to perceived or actual abandonment, violation, and shaming, BPD would be a focal concern. If avoidance of perceived or actual threat of suffering or causing harm in current relationships (along with dysphoria, dissociation, and/or hyperarousal) was debilitating, PTSD would be focal. However, if assessment indicated the presence of affectively charged (or incongruously emotionally numbed) schemas representing self and relationships as simultaneously irreparably damaged but essential and irreplaceable, and this conflict was associated with affective over- as well as underregulation, cPTSD offers a unique focus distinct from that of either BPD or PTSD. This formulation could demystify complex pathological adaptations for the client and clinician, drawing on mechanisms known to underlie PTSD and BPD without attempting to artificially graft the two of them together (along with other comorbid diagnoses) and unnecessarily increasing the cost and 
burden due to multiply layered treatment, as well the risk of treatment failure and stigma [10].

\section{Treatment}

Advances in empirically-supported treatment for both PTSD and BPD illustrate how an integrative CPTSD framework can yield therapeutic advances. Dialectical Behavior Therapy (DBT) is well-established based on efficacy as well as effectiveness research and widespread acceptance by practicing clinicians, yet its primary benefits over and above community treatment by expert clinicians have been shown to be preventing self-harm and enhancing interpersonal functioning by reducing experiential avoidance and expressed anger [209]. These are critically important outcomes, but DBT did not show greater effectiveness than expert treatment as usual (TAU) with regard to guilt, shame, anger suppression, anxiety, core schemas, and impulse control-symptoms that are central to CPTSD. Improvements occurred for recipients of both DBT and TAU, but the utility of those findings is limited by the fact that "expert" treatment cannot easily by deconstructed and taught to other clinicians-and generations of expert therapists have had limited success altering the course of BPD. An intriguing possibility suggested by our review, therefore, but as yet untested, is that clinicians who have become deeply knowledgeable about the challenges of treating individuals with BPD have developed intuitive strategies for helping their clients to understand and gradually gain a sense of mastery of the pervasive distrust and hypervigilance toward their own and other persons' emotions-viewing these as threats-that are common sequelae of traumatic abuse and betrayal and subsequent cPTSD.

Recognizing that traumatic stress reactions may need to be addressed deliberately for many individuals diagnosed with BPD, an adaptation of DBT has been developed with a modified form of Prolonged Exposure (PE) therapy for PTSD. When pilot tested with women meeting criteria for comorbid BPD and PTSD, the trauma-informed DBT yielded similar completion rates $(67-70 \%$ when therapists had acceptable fidelity) and better outcomes for self-harm, depression, anxiety, guilt, and shame than DBT alone [210]. While not referring explicitly to CPTSD, the trauma-informed DBT intervention not only addressed PTSD with the standard features of PE, but specifically modified PE to:

(1) monitor potential negative reactions to exposure (e.g., pre-post exposure ratings of urges to commit suicide and self-injure), (2) target problems that may occur during or as a result of exposure (e.g., dissociation, increased suicide urges), and (3) utilize therapist strategies (e.g., dialectics, irreverence, self-disclosure, validation) that address the particular characteristics of severe BPD patients. In addition, structured procedures for managing common complexities ... during PTSD treatment with this population were used, including strategies to: (1) address multiple traumas, including experiences that do not meet the DSM-IV definition of trauma (e.g., severe verbal abuse), (2) conduct imaginal exposure with fragmented trauma memories, and (3) target unjustified trauma-related shame. In addition, the DBT PE protocol includes a requirement that the protocol be stopped (ideally temporarily) if any form of intentional self-injury recurs.

In other words, by considering the interactive effects of exposure to multiple types and forms of both traumatic victimization and invalidating relationships, the PTSD treatment component was adapted to support the affect, self, and relational regulation necessary to regain trust in self and in sustaining relationships - precisely the goal and focus of cPTSD treatments.

A recent randomized controlled trial study tested the efficacy of a similar combination of trauma processing therapy and DBT (DBT-PTSD) with 74 women diagnosed with PTSD related to childhood sexual abuse [211]. Half of the participants met criteria for comorbid BPD. DBT-PTSD was associated with substantial reductions in PTSD severity for women with or without BPD, while those in a wait-list treatment-as-usual condition showed almost no change (i.e., reductions on average of 33 vs. 2 points on the Clinician Administered PTSD Scale). Dysfunctional behaviors such as self-harm were monitored carefully and did not increase for participants in DBT-PTSD. These findings provide an independent and well-controlled replication demonstrating the efficacy of combining trauma narrative processing with DBT for women with CSA-related PTSD and BPD. Whether the women also met criteria for cPTSD was not assessed and represents a key question for further studies of DBT-PTSD.

The potential for bidirectional synergistic enhancement of treatment for both PTSD and BPD shown by this adaptation of DBT is further illustrated by adaptations to evidence-based therapies for PTSD with clients who are not diagnosed with BPD but have complex trauma histories and CPTSD symptoms and impairments. Structured Therapy for Affective and Interpersonal Regulation with Modified Prolonged Exposure (STAIR-MPE) provides a DBT-informed first phase of therapy aimed at enhancing affect and interpersonal regulation skills, followed by a modification of PE similar to that in $\mathrm{DBT}+\mathrm{PE}$ which carefully titrates trauma memory processing intensity to not exceed the client's affect regulation capabilities. Two randomized controlled trial studies have 
demonstrated STAIR-MPE's efficacy in reducing severe PTSD, depression, and dissociation with women with chronic childhood victimization- or interpersonal violencerelated PTSD [212-214]. Trauma Affect Regulation: Guide for Education and Therapy (TARGET) is an alternative DBT-informed cPTSD therapy, which engages clients in trauma processing with a present-centered cognitive therapy rather than exposure or other trauma memory-focused techniques. TARGET teaches a sequential set of arousal modulation, self-referential focusing, and affect regulation skills designed to reduce avoidance and increase awareness and intentionality in relation to trauma-related internal states in order to address the postulated mechanisms of flashbacks and intrusive memories. In three randomized controlled trial effectiveness studies with adults with cPTSD [13,14,215,216] and one with adolescents [217], TARGET has achieved reductions in PTSD, depression, affect dysregulation, substance use risk, and alienation superior to those of active comparison therapies. Thus, a cPTSD framework informed by BPD clinical phenomenology and therapeutic approaches has resulted in promising innovations that can make therapy more effective and accessible for trauma survivors whose affect, self, and interpersonal dysregulation otherwise may bar them from, or lead them to refuse, PTSD treatment $[11,12]$.

\section{Research}

At a foundational level, the scientific challenge is to develop and test a nomologically- systematic and empirically-grounded theory of interrelationships of: (1) biosocial diatheses (e.g., genetic/familial/ neurobiological risk/protective factors), (2) attachment/relational (e.g., absent or poorly attuned caregiving) and more frankly traumatic (e.g., physical or sexual abuse) stressors separately and in varied combinations (e.g., caregiverperpetrated abuse or attachment-disrupting family violence), and (3) developmental trajectories (e.g., biopsychosocial adaptations leading to static or changing functioning) in the domains of impairment, resilience, or optimal growth and functioning, in order to disentangle the associations among BPD, PTSD, and CPTSD.

More specifically, a systematic comparison of how the three syndromes differ on the National Institute of Mental Health's Research Domain Criteria (RDOCs) [218] could clarify the syndromes' construct validity (or lack thereof) and point toward clinical and translational studies of targeted assessment, diagnostic, and therapeutic protocols. For example, in the RDOC "negative valence systems" PTSD should be particularly associated with acute or sustained threat and BPD with frustrative nonreward, while the two would be expected to overlap on the criteria of anxiety and loss, across the range of units of analysis from genes to physiology to behavior and self-report. cPTSD would be theoretically and clinically supported if there was evidence of unique profile(s) across the criteria and units of analysis distinct from both BPD and PTSD (e.g., specific genetic and familial vulnerability to anxiety and frustrative nonreward on the physiological, behavioral, and psychological level following sustained threat and loss). The accuracy of identification of distinct profiles for BPD, PTSD, and CPTSD is likely to increase dramatically when other RDOC domains (i.e., positive valence and arousal/ regulatory systems, cognitive and social processes) are included in characterizing the adaptations made by sub-groups with different diathesis-stressor histories. BPD's sensitivity to abandonment and rejection, PTSD's arousal and positive affect dysregulation, and cPTSD's altered declarative memory, hypo-arousal, and self-perception are potential foci for a more differentiated description of core impairments that could justify distinct classifications and better tailored treatment strategiess.

Empirically identified targets for assessment and diagnosis are critical to refined therapeutic interventions for BPD, PTSD, and CPTSD. For example, comorbid $\mathrm{BPD}+\mathrm{PTSD}$ may be responsive to the distress tolerance and avoidance-reduction therapies which have strong evidence bases for those disorders. However, the high drop-out rate reported even by potentially efficacious combined BPD+PTSD interventions [210] may signal the need for alternative therapeutic frameworks such as those offered by CPTSD therapies that do not modify exposure-based interventions but instead directly address dissociation [213] or severe affect dysregulation [215]. The SMART adaptive treatment research paradigm provides an efficient approach to matching non-responders to alternative therapeutic approaches based on characteristics (e.g., RDOC criteria) that are not targeted by first line evidence-based treatments but commonly present among non-responders [219]. Rather than fitting recipients to the therapy, this approach to treatment research matches therapies to recipient characteristics when this is necessary to reduce the number needed to treat for successful outcomes. RDOC-like profiles of BPD, PTSD, and CPTSD could provide a rational and efficient basis for SMART treatment outcome research, as well as for refinements in the specific processes and interventions used by each therapy in order to address key features of specific syndromes.

\section{Conclusion}

This review has summarized current clinical and scientific findings regarding comorbidity, clinical phenomenology and neurobiology of BPD, PTSD, and CPTSD, The role of traumatic victimization in general and relational/ attachment trauma specific to primary caregivers, dissociation, and affect dysregulation were highlighted. The etiology and course of BPD involves heterogeneity related to psychological trauma that includes, but extends beyond, comorbidity with PTSD and potentially involves childhood 
victimization-related affect dysregulation and dissociation consistent with a cPTSD framework. Although BPD and cPTSD overlap substantially (as do cPTSD and PTSD), it is unwarranted to conceptualize CPTSD either as a replacement for or sub-type of BPD. The evidence instead suggests that a sub-group of BPD patients-who often but not always have comorbid PTSD-may be best understood and treated if cPTSD is explicitly addressed as well-and in some cases, in lieu of-BPD. A better differentiated empirically-grounded view of cPTSD, BPD, and PTSD is a high priority for the advancement of clinical practice and research with traumatized adults.

\section{Competing interests}

Julian Ford is co-owner of Advanced Trauma Solutions, Inc., the distributor of the TARGET@ complex trauma treatment model licensed by the University of Connecticut.

Christine Courtois has no competing interests.

\section{Authors' contributions}

JF designed the review's organization, conducted the literature review, and was the lead writer. CC provided input to the review's organization and literature review, and co-wrote or edited sections of the manuscript. Both authors read and approved the final manuscript.

\section{Acknowledgements}

Support for writing of the paper was provided by a grant from the Substance Abuse and Mental Health Services Administration, 1SM061273-01 (J. Ford, Principal Investigator).

\section{Author details}

'University of Connecticut Health Center MC1410, 263 Farmington Avenue, Farmington, CT 06030-1410, USA. ${ }^{2}$ Independent Pactice, Washington, DC, Elements Behavioral Health, Promises, Malibu, CA, USA.

\section{Received: 13 March 2014 Accepted: 18 May 2014}

Published: 9 July 2014

\section{References}

1. D'Andrea W, Ford JD, Stolbach B, Spinazzola J, van der Kolk BA: Understanding interpersonal trauma in children: why we need a developmentally appropriate trauma diagnosis. Am J Orthopsychiatry 2012, 82(2):187-200. doi:10.1111/j.1939-0025.2012.01154.x

2. Golier JA, Yehuda R, Bierer LM, Mitropoulou V, New AS, Schmeidler J, Siever $\mathrm{L}$ : The relationship of borderline personality disorder to posttraumatic stress disorder and traumatic events. Am J Psychiatr 2003, 160(11):2018-2024

3. Herman JL, Van der Kolk BA: Traumatic antecedents of borderline personality disorder. In Psychological trauama. Edited by Van der Kolk B. Washington DC: American Psychiatric Association; 1987:111-126.

4. Westphal M, Olfson M, Bravova M, Gameroff MJ, Gross R, Wickramaratne P Neria Y: Borderline personality disorder, exposure to interpersonal trauma, and psychiatric comorbidity in urban primary care patients. Psychiatry 2013, 76(4):365-380. doi:10.1521/psyc.2013.76.4.365.

5. Yen S, Shea MT, Battle CL, Johnson DM, Zlotnick C, Dolan-Sewell R, McGlashan TH: Traumatic exposure and posttraumatic stress disorder in borderline, schizotypal, avoidant, and obsessive-compulsive personality disorders: findings from the collaborative longitudinal personality disorders study. J Nerv Ment Disord 2002, 190(8):510-518. doi:10.1097/01. NMD.0000026620.66764.78

6. Lewis KL, Grenyer BF: Borderline personality or complex posttraumatic stress disorder? An update on the controversy. Harv Rev Psychiatry 2009, 17(5):322-328. doi:10.3109/10673220903271848.

7. Vermetten E, Spiegel D: Trauma and dissociation: implications for borderline personality disorder. Curr Psychiatr Rep 2014, 16(2):434. doi:10.1007/s11920-013-0434-8.

8. Zanarini MC, Frankenburg FR, Fitzmaurice G: Defense mechanisms reported by patients with borderline personality disorder and axis II comparison subjects over 16 years of prospective follow-up: description and prediction of recovery. [Comparative Study Research Support, N.I.H., Extramural]. Am J Psychiatr 2013, 170(1):111-120. doi:10.1176/appi. ajp.2012.12020173.

9. Zanarini MC, Laudate CS, Frankenburg FR, Wedig MM, Fitzmaurice G Reasons for self-mutilation reported by borderline patients over 16 years of prospective follow-up. J Personal Disord 2013, 27(6):783-794. doi:10.1521/pedi_2013_27_115.

10. Herman JL: Complex PTSD: a syndrome in survivors of prolonged and repeated trauma. [Print]. J Trauma Stress 1992, 5(3):377-391.

11. Spinazzola J, Blaustein $M$, van der Kolk BA: Posttraumatic stress disorder treatment outcome research: the study of unrepresentative samples? J Trauma Stress 2005, 18(5):425-436. doi:10.1002/jts.20050.

12. Spinazzola J, Ford JD, Zucker M, van der Kolk BA, Silva S, Smith SF, Blaustein M: "National survey on complex trauma exposure, outcome, and intervention among children and adolescents": errata. Psychiatr Ann 2005, 35(8):624.

13. Ford JD, Chang R, Levine J, Zhang W: Randomized clinical trial comparing affect regulation and supportive group therapies for victimization-related PTSD with incarcerated women. Behav Ther 2013, 44(2):262-276. doi:10.1016/.jbeth.2012.10.003

14. Ford JD, Grasso D, Greene C, Levine J, Spinazzola J, van der Kolk B: Clinical significance of a proposed developmental trauma disorder diagnosis: results of an international survey of clinicians. [Research Support, Non-U. S. Gov't]. J Clin Psychiatry 2013, 74(8):841-849. doi:10.4088/JCP.12m08030.

15. First MB: Clinical utility: a prerequisite for the adoption of a dimensional approach in DSM. J Abnorm Psychol 2005, 114(4):560-564. doi:10.1037/ $0021-843 \times 114.4 .560$

16. Herman JL: CPTSD is a distinct entity: comment on Resick et al. (2012). J Trauma Stress 2012, 25(3):256-257. doi:10.1002/jts.21697.

17. Resick PA, Bovin MJ, Calloway AL, Dick AM, King MW, Mitchell KS, Wolf EJ: A critical evaluation of the complex PTSD literature: implications for DSM-5. [Review]. J Trauma Stress 2012, 25(3):241-251. doi:10.1002/jts.21699.

18. Driessen M, Beblo T, Reddemann L, Rau H, Lange W, Silva A, Ratzka S: Is the borderline personality disorder a complex post-traumatic stress disorder? - The state of research. Review. Nervenarzt 2002, 73(9):820-829. doi:10.1007/s00115-002-1296-1.

19. Grant BF, Chou SP, Goldstein RB, Huang B, Stinson FS, Saha TD, Ruan WJ: Prevalence, correlates, disability, and comorbidity of DSM-IV borderline personality disorder: results from the wave 2 national epidemiologic survey on alcohol and related conditions. J Clin Psychiatry 2008, 69(4):533-545

20. Kawakami N, Tsuchiya M, Umeda M, Koenen KC, Kessler RC, World Mental Health Survey, J: Trauma and posttraumatic stress disorder in Japan: results from the World Mental Health Japan Survey. J Psychiatr Res 2014, 53:157-165. doi:10.1016/j.jpsychires.2014.01.015.

21. Kessler RC, Petukhova M, Sampson NA, Zaslavsky AM, Wittchen HU: Twelve-month and lifetime prevalence and lifetime morbid risk of anxiety and mood disorders in the United States. [Research Support, N.I. H., Extramural Research Support, Non-U.S. Gov't]. Int I Methods Psychiatr Res 2012, 21(3):169-184. doi:10.1002/mpr.1359.

22. Eichelman B: Borderline personality disorder, PTSD, and suicide. Am J Psychiatr 2010, 167(10):1152-1154. doi:10.1176/appi.ajp.2010.10060870.

23. Pagura J, Stein MB, Bolton JM, Cox BJ, Grant B, Sareen J: Comorbidity of borderline personality disorder and posttraumatic stress disorder in the U.S. population. [Research Support, N.I.H., Extramural Research Support, Non-U.S. Gov't]. J Psychiatr Res 2010, 44(16):1190-1198. doi:10.1016/j. jpsychires.2010.04.016.

24. Zanarini MC, Frankenburg FR, DeLuca CJ, Hennen J, Khera GS, Gunderson JG: The pain of being borderline: dysphoric states specific to borderline personality disorder. Harv Rev Psychiatn 1998, 6(4):201-207.

25. Zlotnick C, Johnson DM, Yen S, Battle CL, Sanislow CA, Skodol AE, Shea MT: Clinical features and impairment in women with Borderline Personality Disorder (BPD) with Posttraumatic Stress Disorder (PTSD), BPD without PTSD, and other personality disorders with PTSD. J Nerv Ment Dis 2003, 191(11):706-713. doi:10.1097/01.nmd.0000095122.29476.ff.

26. Zanarini MC, Frankenburg FR, Weingeroff JL, Reich DB, Fitzmaurice GM, Weiss RD: The course of substance use disorders in patients with borderline personality disorder and Axis II comparison subjects: a 10-year follow-up study. Addiction 2011, 106(2):342-348. doi:10.1111/j.1360-0443.2010.03176.x.

27. Zanarini MC, Horz S, Frankenburg FR, Weingeroff J, Reich DB, Fitzmaurice G: The 10-year course of PTSD in borderline patients and axis II comparison 
subjects. Acta Psychiatr Scand 2011, 124(5):349-356. doi:10.1111/j.16000447.2011.01717.x

28. Courtois CA: Healing the Incest Wound: Adult Survivors in Therapy. New York: W. W. Norton; 1988/2009.

29. Duckworth T, Follette $V$ (Eds): Retraumatization. New York: Routledge; 2012.

30. Dorrepaal E, Thomaes K, Smit JH, Hoogendoorn A, Veltman DJ, van Balkom AJ, Draijer N: Clinical phenomenology of childhood abuse-related complex PTSD in a population of female patients: patterns of personality disturbance. J Trauma Dissociation 2012, 13(3):271-290. doi:10.1080/ 15299732.2011 .641496

31. Ford JD: Disorders of extreme stress following war-zone military trauma: associated features of posttraumatic stress disorder to comorbid but distinct syndromes? J Consult Clin Psychol 1999, 67(1):3-12.

32. Ford JD, Fournier D: Psychological trauma and post-traumatic stress disorder among women in community mental health aftercare following psychiatric intensive care. J Psychiatr Intensive Care 2007, 3(1):27-34.

33. Ford JD, Smith S: Complex posttraumatic stress disorder in trauma-exposed adults receiving public sector outpatient substance abuse disorder treatment. Addiction Res Theor 2008, 16(2):193-203.

34. McLean LM, Gallop R: Implications of childhood sexual abuse for adult borderline personality disorder and complex posttraumatic stress disorder. Am J Psychiatr 2003, 160(2):369-371.

35. Van Dijke A, Ford JD, Van der Hart O, Van Son M, van der Heijden P, Bühring M: Complex posttraumatic stress disorder in patients with borderline personality disorder and somatoform disorders. Psychol Trauma 2011, 4:162-168.

36. van Dijke A, Ford JD, van der Hart O, Van Son MJ, Van der Heijden PG, Buhring M: Childhood traumatization by primary caretaker and affect dysregulation in patients with borderline personality disorder and somatoform disorder. Eur J Psychotraumatol 2011, 2. doi:10.3402/ejpt. v2i0.5628.

37. Roepke S, Vater A, Preissler S, Heekeren HR, Dziobek I: Social cognition in borderline personality disorder. Front Neurosci 2012, 6:195. doi:10.3389/ fnins.2012.00195.

38. Weniger $G$, Lange $C$, Sachsse $U$, Irle E: Reduced amygdala and hippocampus size in trauma-exposed women with borderline personality disorder and without posttraumatic stress disorder. J Psychiatry Neurosci 2009, 34(5):383-388.

39. Wedig MM, Frankenburg FR, Bradford Reich D, Fitzmaurice G, Zanarini MC: Predictors of suicide threats in patients with borderline personality disorder over 16 years of prospective follow-up. Psychiatry Res 2013, 208(3):252-256. doi:10.1016/j.psychres.2013.05.009.

40. Harned MS, Rizvi SL, Linehan MM: Impact of co-occurring posttraumatic stress disorder on suicidal women with borderline personality disorder. Am J Psychiatr 2010, 167(10):1210-1217. doi:10.1176/appi.ajp.2010.09081213.

41. Zlotnick C, Mattia Jl, Zimmerman M: Clinical correlates of self-mutilation in a sample of general psychiatric patients. J Nerv Ment Dis 1999, 187(5):296-301.

42. Schroeder K, Fisher HL, Schafer I: Psychotic symptoms in patients with borderline personality disorder: prevalence and clinical management. Curr Opin Psychiatr 2013, 26(1):113-119. doi:10.1097/YCO.0b013e32835a2ae7.

43. Rusch N, Corrigan PW, Bohus M, Kuhler T, Jacob GA, Lieb K: The impact of posttraumatic stress disorder on dysfunctional implicit and explicit emotions among women with borderline personality disorder. J NerV Ment Dis 2007, 195(6):537-539. doi:10.1097/NMD.0b013e318064e7fc.

44. Rusch N, Luders E, Lieb K, Zahn R, Ebert D, Thompson PM, van Elst LT: Corpus callosum abnormalities in women with borderline personality disorder and comorbid attention-deficit hyperactivity disorder. J Psychiatry Neurosci 2007, 32(6):417-422.

45. Rusch N, Schulz D, Valerius G, Steil R, Bohus M, Schmahl C: Disgust and implicit self-concept in women with borderline personality disorder and posttraumatic stress disorder. Eur Arch Psychiatry Clin Neurosci 2011, 261(5):369-376. doi:10.1007/s00406-010-0174-2

46. Frankenburg FR, Zanarini MC: Obesity and obesity-related illnesses in borderline patients. J Personal Disord 2006, 20(1):71-80. doi:10.1521/ pedi.2006.20.1.71.

47. Niedtfeld I, Schulze L, Krause-Utz A, Demirakca T, Bohus M, Schmahl C: Voxel-based morphometry in women with borderline personality disorder with and without comorbid posttraumatic stress disorder. PLOS ONE 2013, 8(6):e65824. doi:10.1371/journal.pone.0065824.
48. Ludascher P, Valerius G, Stiglmayr C, Mauchnik J, Lanius RA, Bohus M, Schmahl C: Pain sensitivity and neural processing during dissociative states in patients with borderline personality disorder with and without comorbid posttraumatic stress disorder: a pilot study. J Psychiatry Neurosci 2010, 35(3):177-184.

49. Schmahl C, Berne K, Krause A, Kleindienst N, Valerius G, Vermetten E, Bohus $\mathrm{M}$ : Hippocampus and amygdala volumes in patients with borderline personality disorder with or without posttraumatic stress disorder. J Psychiatry Neurosci 2009, 34(4):289-295.

50. Hoerst M, Weber-Fahr W, Tunc-Skarka N, Ruf M, Bohus M, Schmahl C, Ende $\mathrm{G}$ : Metabolic alterations in the amygdala in borderline personality disorder: a proton magnetic resonance spectroscopy study. Biol Psychiatry 2010, 67(5):399-405. doi:10.1016/j.biopsych.2009.09.030.

51. Dixon-Gordon KL, Gratz KL, Breetz A, Tull M: A laboratory-based examination of responses to social rejection in borderline personality disorder: the mediating role of emotion dysregulation. J Personal Disord 2013, 27(2):157-171. doi:10.1521/pedi.2013.27.2.157.

52. Dixon-Gordon KL, Gratz KL, Tull MT: Multimodal assessment of emotional reactivity in borderline personality pathology: the moderating role of posttraumatic stress disorder symptoms. Compr Psychiatry 2013, 54(6):639-648. doi:10.1016/j.comppsych.2012.12.019.

53. Wingenfeld K, Lange W, Wulff H, Berea C, Beblo T, Saavedra AS, Driessen M: Stability of the dexamethasone suppression test in borderline personality disorder with and without comorbid PTSD: a one-year follow-up study. J Clin Psychol 2007, 63(9):843-850. doi:10.1002/jclp.20396.

54. Gratz KL, Tull MT: Exploring the relationship between posttraumatic stress disorder and deliberate self-harm: the moderating roles of borderline and avoidant personality disorders. Psychiatry Res 2012, 199(1):19-23. doi:10.1016/j.psychres.2012.03.025.

55. Maurex L, Lekander M, Nilsonne A, Andersson EE, Asberg M, Ohman A: Social problem solving, autobiographical memory, trauma, and depression in women with borderline personality disorder and a history of suicide attempts. Br J Clin Psychol 2010, 49(Pt 3):327-342. doi:10.1348/ 014466509X454831.

56. Zlotnick C, Franklin CL, Zimmerman M: Is comorbidity of posttraumatic stress disorder and borderline personality disorder related to greater pathology and impairment? Am J Psychiatr 2002, 159(11):1940-1943.

57. Zweig-Frank H, Paris J, Guzder J: Psychological risk factors and self-mutilation in male patients with BPD. [Research Support, Non-U.S. Gov't]. Can J Psychiatry 1994, 39(5):266-268.

58. Zweig-Frank H, Paris J, Guzder J: Psychological risk factors for dissociation and self-mutilation in female patients with borderline personality disorder. [Research Support, Non-U.S. Gov't]. Can J Psychiatry 1994, 39(5):259-264.

59. Cloitre M, Garvert DW, Brewin CR, Bryant RA, Maercker A: Evidence for proposed ICD-11 PTSD and complex PTSD: a latent profile analysis. Eur J Psychotraumatol 2013, 4. doi:10.3402/ejpt.v4i0.20706.

60. Zanarini MC, Frankenburg FR, Dubo ED, Sickel AE, Trikha A, Levin A, Reynolds V: Axis I comorbidity of borderline personality disorder. Am J Psychiatr 1998, 155(12):1733-1739.

61. Zanarini MC, Frankenburg FR, Dubo ED, Sickel AE, Trikha A, Levin A, Reynolds V: Axis II comorbidity of borderline personality disorder. Compr Psychiatry 1998, 39(5):296-302.

62. Freyd JJ, DePrince AP, Gleaves DH: The state of betrayal trauma theory: reply to McNally-conceptual issues and future directions. Memory 2007 15(3):295-311.

63. Lis $\mathrm{S}$, Bohus M: Social interaction in borderline personality disorder. [Review]. Curr Psychiatr Rep 2013, 15(2):338. doi:10.1007/s11920-012-0338-Z

64. Schmahl CG, Elzinga BM, Ebner UW, Simms T, Sanislow C, Vermetten E, Bremner JD: Psychophysiological reactivity to traumatic and abandonment scripts in borderline personality and posttraumatic stress disorders: a preliminary report. Psychiatry Res 2004, 126(1):33-42. doi:10.1016/j.psychres.2004.01.005.

65. Sack M, Sachsse U, Overkamp B, Dulz B: Trauma-related disorders in patients with borderline personality disorders. Results of a multicenter study. Nervenarzt 2013, 84(5):608-614. doi:10.1007/s00115-012-3489-6.

66. Zanarini MC, Frankenburg FR, Reich DB, Hennen J, Silk KR: Adult experiences of abuse reported by borderline patients and Axis II comparison subjects over six years of prospective follow-up. J Nerv Ment Dis 2005, 193(6):412-416.

67. Zanarini MC, Frankenburg FR, Reich DB, Marino MF, Haynes MC, Gunderson JG: Violence in the lives of adult borderline patients. J Nerv Ment Dis 1999, 187(2):65-71. 
68. Zanarini MC, Gunderson JG, Marino MF, Schwartz EO, Frankenburg FR: Childhood experiences of borderline patients. Compr Psychiatry 1989, 30(1):18-25

69. Zanarini MC, Williams AA, Lewis RE, Reich RB, Vera SC, Marino MF, Frankenburg FR: Reported pathological childhood experiences associated with the development of borderline personality disorder. Am J Psychiatr 1997, 154(8):1101-1106.

70. Zanarini MC, Yong L, Frankenburg FR, Hennen J, Reich DB, Marino MF, Vujanovic AA: Severity of reported childhood sexual abuse and its relationship to severity of borderline psychopathology and psychosocial impairment among borderline inpatients. J Nerv Ment Dis 2002, 190(6):381-387.

71. Laporte L, Paris J, Guttman H, Russell J: Psychopathology, childhood trauma, and personality traits in patients with borderline personality disorder and their sisters. J Personal Disord 2011, 25(4):448-462. doi:10.1521/pedi.2011.25.4.448.

72. O'Brien BS, Sher L: Child sexual abuse and the pathophysiology of suicide in adolescents and adults. [Review]. Int J Adolesc Med Health 2013, 25(3):201-205. doi:10.1515/ijamh-2013-0053.

73. Wingenfeld K, Schaffrath C, Rullkoetter N, Mensebach C, Schlosser N, Beblo T, Meyer B: Associations of childhood trauma, trauma in adulthood and previous-year stress with psychopathology in patients with major depression and borderline personality disorder. Child Abuse Negl 2011, 35(8):647-654. doi:10.1016/j.chiabu.2011.04.003.

74. Cerutti R, Manca M, Presaghi F, Gratz KL: Prevalence and clinical correlates of deliberate self-harm among a community sample of Italian adolescents. J Adolesc 2011, 34(2):337-347. doi:10.1016/j.adolescence.2010.04.004.

75. Newnham EA, Janca A: Childhood adversity and borderline personality disorder: a focus on adolescence. Curr Opin Psychiatr 2014, 27(1):68-72. doi:10.1097/YC0.0000000000000028

76. Herman JL, Perry JC, van der Kolk BA: Childhood trauma in borderline personality disorder. [Case Reports Research Support, U.S. Gov't, P.H.S.] Am J Psychiatr 1989, 146(4):490-495

77. Bornovalova MA, Levy R, Gratz KL, Lejuez CW: Understanding the heterogeneity of BPD symptoms through latent class analysis: initial results and clinical correlates among inner-city substance users. Psychol Assess 2010, 22(2):233-245. doi:10.1037/a0018493.

78. Frankenburg FR, Zanarini MC: The association between borderline personality disorder and chronic medical illnesses, poor health-related lifestyle choices, and costly forms of health care utilization. [Comparative Study Research Support, U.S. Gov't, P.H.S.]. J Clin Psychiatry 2004, 65(12):1660-1665.

79. Zanarini MC, Frankenburg FR, Reich DB, Marino MF, Lewis RE, Williams AA, Khera GS: Biparental failure in the childhood experiences of borderline patients. J Personal Disord 2000, 14(3):264-273.

80. Ball JS, Links PS: Borderline personality disorder and childhood trauma: evidence for a causal relationship. Curr Psychiatr Rep 2009, 11(1):63-68.

81. Bradley R, Jenei J, Westen D: Etiology of borderline personality disorder: disentangling the contributions of intercorrelated antecedents. [Research Support, U.S. Gov't, P.H.S.]. J Nerv Ment Dis 2005, 193(1):24-31.

82. McGowan A, King H, Frankenburg FR, Fitzmaurice G, Zanarini MC: The course of adult experiences of abuse in patients with borderline personality disorder and Axis II comparison subjects: a 10-year follow-up study. J Personal Disord 2012, 26(2):192-202. doi:10.1521/pedi.2012.26.2.192.

83. Putnam KM, Silk KR: Emotion dysregulation and the development of borderline personality disorder. Dev Psychopathol 2005, 17(4):899-925.

84. Carpenter RW, Tomko RL, Trull TJ, Boomsma DI: Gene-environment studies and borderline personality disorder: a review. [Review]. Curr Psychiatr Rep 2013, 15(1):336. doi:10.1007/s11920-012-0336-1.

85. Grilo CM, Sanislow CA, Gunderson JG, Pagano ME, Yen S, Zanarini MC, McGlashan TH: Two-year stability and change of schizotypal, borderline, avoidant, and obsessive-compulsive personality disorders. [Research Support, U.S. Gov't, P.H.S.]. J Consult Clin Psychol 2004, 72(5):767-775. doi:10.1037/0022-006X.72.5.767.

86. Zanarini MC, Barison LK, Frankenburg FR, Reich DB, Hudson Jl: Family history study of the familial coaggregation of borderline personality disorder with axis I and nonborderline dramatic cluster axis II disorders. [Comparative Study Research Support, N.I.H., Extramural]. J Pers Disord 2009, 23(4):357-369. doi:10.1521/pedi.2009.23.4.357.

87. Zanarini MC, Frankenburg FR: Pathways to the development of borderline personality disorder. [Research Support, U.S. Gov't, P.H.S.]. J Personal Disord 1997, 11(1):93-104.
88. Zanarini MC, Frankenburg FR: The essential nature of borderline psychopathology. J Personal Disord 2007, 21(5):518-535. doi:10.1521/ pedi.2007.21.5.518

89. Gunderson JG, Lyons-Ruth K: BPD's interpersonal hypersensitivity phenotype: a gene-environment-developmental model. J Pers Disord 2008, 22(1):22-41. doi:10.1521/pedi.2008.22.1.22.

90. Lyons-Ruth K: Contributions of the mother-infant relationship to dissociative, borderline, and conduct symptoms in young adulthood. Infant Ment Health $J$ 2008, 29(3):203-218. doi:10.1002/imhj.20173.

91. Gunderson JG, Weinberg I, Daversa MT, Kueppenbender KD, Zanarini MC, Shea MT, Dyck I: Descriptive and longitudinal observations on the relationship of borderline personality disorder and bipolar disorder. [Comparative Study Research Support, N.I.H., Extramural]. Am J Psychiatry 2006, 163(7):1173-1178. doi:10.1176/appi.ajp.163.7.1173.

92. Zimmerman M, Mattia Jl: Axis I diagnostic comorbidity and borderline personality disorder. Compr Psychiatry 1999, 40(4):245-252.

93. Zimmerman M, Rothschild L, Chelminski I: The prevalence of DSM-IV personality disorders in psychiatric outpatients. Am J Psychiatr 2005, 162(10):1911-1918. doi:10.1176/appi.ajp.162.10.1911.

94. Frankenburg FR, Fitzmaurice GM, Zanarini MC: The use of prescription opioid medication by patients with borderline personality disorder and axis II comparison subjects: a 10-year follow-up study. J Clin Psychiatry 2014, doi:10.4088/JCP.13m08557.

95. Krause-Utz A, Sobanski E, Alm B, Valerius G, Kleindienst N, Bohus M, Schmahl $\mathrm{C}$ : Impulsivity in relation to stress in patients with borderline personality disorder with and without co-occurring attention-deficit/hyperactivity disorder: an exploratory study. [Comparative Study]. J Nerv Ment Dis 2013, 201(2):116-123. doi:10.1097/NMD.0b013e31827f6462

96. Perugi G, Angst J, Azorin JM, Bowden C, Vieta E, Young AH, Group, B. S: The bipolar-borderline personality disorders connection in major depressive patients. Acta Psychiatr Scand 2013, 128(5):376-383. doi:10.1111/acps.12083.

97. Perugi G, Angst J, Azorin JM, Bowden C, Vieta E, Young AH, Group, B. S: Is comorbid borderline personality disorder in patients with major depressive episode and bipolarity a developmental subtype? Findings from the international BRIDGE study. J Affect Disord 2013, 144(1-2):72-78. doi:10.1016/j.jad.2012.06.008

98. Wedig MM, Silverman MH, Frankenburg FR, Reich DB, Fitzmaurice G, Zanarini MC: Predictors of suicide attempts in patients with borderline personality disorder over 16 years of prospective follow-up. Psychol Med 2012, 42(11):2395-2404. doi:10.1017/S0033291712000517.

99. Yen S, Gagnon K, Spirito A: Borderline personality disorder in suicidal adolescents. Personal Ment Health 2013, 7(2):89-101. doi:10.1002/pmh.1216.

100. Zimmerman M, Martinez J, Young D, Chelminski I, Morgan TA, Dalrymple K: Comorbid bipolar disorder and borderline personality disorder and history of suicide attempts. J Personal Disord 2013, doi:10.1521/ pedi_2013_27_122.

101. Alvarez MJ, Roura P, Oses A, Foguet Q, Sola J, Arrufat FX: Prevalence and clinical impact of childhood trauma in patients with severe mental disorders. J Nerv Ment Dis 2011, 199(3):156-161. doi:10.1097/ NMD.0b013e31820c751c

102. Bierer LM, Yehuda R, Schmeidler J, Mitropoulou V, New AS, Silverman JM, Siever LJ: Abuse and neglect in childhood: relationship to personality disorder diagnoses. [Research Support, U.S. Gov't, Non-P.H.S. Research Support, U.S. Gov't, P.H.S.]. CNS Spectrums 2003, 8(10):737-754.

103. Tarrier N, Picken A: Co-morbid PTSD and suicidality in individuals with schizophrenia and substance and alcohol abuse. Soc Psychiatry Psychiatr Epidemiol 2011, 46(11):1079-1086. doi:10.1007/s00127-010-0277-0.

104. Scoboria A, Ford J, Lin HJ, Frisman L: Exploratory and confirmatory factor analyses of the structured interview for disorders of extreme stress. Assessment 2008, 15(4):404-425. doi:10.1177/1073191108319005.

105. de Jong J, Komproe $\mathrm{H}$, Spinazzola J, van der Kolk BA, Van Ommeren MH: DESNOS in three postconflict settings: assessing cross-cultural construct equivalence. J Trauma Stress 2005, 18(1):13-21.

106. McLaughlin KA, Green JG, Gruber MJ, Sampson NA, Zaslavsky AM, Kessler RC: Childhood adversities and adult psychopathology in the National Comorbidity Survey Replication (NCS-R) III: associations with functional impairment related to DSM-IV disorders. Psychol Med 2010, 40(5):847-859 doi:10.1017/S0033291709991115.

107. Green JG, McLaughlin KA, Berglund PA, Gruber MJ, Sampson NA, Zaslavsky AM, Kessler RC: Childhood adversities and adult psychiatric disorders in the national comorbidity survey replication I: associations with first 
onset of DSM-IV disorders. Arch Gen Psychiatry 2010, 67(2):113-123. doi:10.1001/archgenpsychiatry.2009.186.

108. Ford JD: Posttraumatic stress disorder and psychological trauma. In Drug abuse and addiction in medical illness: causes, consequences, and treatment. Edited by Verster J, Brady K, Galanter M, Conrod PJ. Totowa, NJ: Springer/Humana Press; 2013:335-342.

109. Assion HJ, Brune N, Schmidt N, Aubel T, Edel MA, Basilowski M, Frommberger U: Trauma exposure and post-traumatic stress disorder in bipolar disorder. Soc Psychiatry Psychiatr Epidemiol 2009, 44(12):10411049. doi:10.1007/500127-009-0029-1.

110. Strawn JR, Adler CM, Fleck DE, Hanseman D, Maue DK, Bitter S, DelBello MP: Post-traumatic stress symptoms and trauma exposure in youth with first episode bipolar disorder. Early Interv Psychiatry 2010, 4(2):169-173. doi:10.1111/j.1751-7893.2010.00173.x.

111. Berenbaum H, Thompson RJ, Milanek ME, Boden MT, Bredemeier K: Psychological trauma and schizotypal personality disorder. J Abnorm Psychol 2008, 117(3):502-519. doi:10.1037/0021-843X.117.3.502

112. Lataster J, Myin-Germeys I, Lieb R, Wittchen HU, van Os J: Adversity and psychosis: a 10-year prospective study investigating synergism between early and recent adversity in psychosis. [Research Support, Non-U.S. Gov't]. Acta Psychiatr Scand 2012, 125(5):388-399. doi:10.1111/j.16000447.2011.01805.x.

113. Dell PF: Axis II pathology in outpatients with dissociative identity disorder. J Nerv Ment Dis 1998, 186(6):352-356.

114. Tsai J, Harpaz-Rotem I, Pilver CE, Wolf EJ, Hoff RA, Levy KN, Pietrzak RH: Latent class analysis of personality disorders in adults with posttraumatic stress disorder: results from the National Epidemiologic Survey on Alcohol and Related Conditions. J Clin Psychiatry 2013, doi:10.4088/JCP.13m08466.

115. Rusch N, Holzer A, Hermann C, Schramm E, Jacob GA, Bohus M, Corrigan PW: Self-stigma in women with borderline personality disorder and women with social phobia. J Nerv Ment Dis 2006 194(10):766-773. doi:10.1097/01.nmd.0000239898.48701.dc

116. Mauchnik J, Schmahl C: The latest neuroimaging findings in borderline personality disorder. [Review]. Curr Psychiatr Rep 2010, 12(1):46-55. doi:10.1007/s11920-009-0089-7.

117. Rusch N, Bracht T, Kreher BW, Schnell S, Glauche V, II'yasov KA, van Elst LT: Reduced interhemispheric structural connectivity between anterior cingulate cortices in borderline personality disorder. Psychiatry Res 2010, 181(2):151-154. doi:10.1016/.jpscychresns.2009.08.004.

118. Koenigsberg HW, Denny BT, Fan J, Liu X, Guerreri S, Mayson SJ, Siever $L$ : The neural correlates of anomalous habituation to negative emotional pictures in borderline and avoidant personality disorder patients. Am J Psychiatr 2014, 171(1):82-90. doi:10.1176/appi. ajp.2013.13070852

119. Lanius RA, Brand B, Vermetten E, Frewen PA, Spiegel D: The dissociative subtype of posttraumatic stress disorder: rationale, clinical and neurobiological evidence, and implications. Depress Anxiety 2012, 29(8):701-708. doi:10.1002/da.21889.

120. New AS, Hazlett EA, Newmark RE, Zhang J, Triebwasser J, Meyerson D, Buchsbaum MS: Laboratory induced aggression: a positron emission tomography study of aggressive individuals with borderline personality disorder. Biol Psychiatry 2009, 66(12):1107-1114. doi:10.1016/j. biopsych.2009.07.015

121. Krause-Utz A, Winter D, Niedtfeld I, Schmahl C: The latest neuroimaging findings in borderline personality disorder. Curr Psychiatr Rep 2014 16(3):438. doi:10.1007/s11920-014-0438-z.

122. Andersen SL, Tomada A, Vincow ES, Valente E, Polcari A, Teicher MH: Preliminary evidence for sensitive periods in the effect of childhood sexual abuse on regional brain development. J Neuropsychiatry Clin Neurosci 2008, 20(3):292-301. doi:10.1176/appi.neuropsych.20.3.292.

123. Brown VM, Labar KS, Haswell CC, Gold AL, Mid-Atlantic MW, Beall SK Morey RA: Altered resting-state functional connectivity of basolateral and centromedial amygdala complexes in posttraumatic stress disorder. Neuropsychopharmacology 2013, doi:10.1038/ npp.2013.197

124. Cisler JM, James GA, Tripathi S, Mletzko T, Heim C, Hu XP, Kilts CD: Differential functional connectivity within an emotion regulation neural network among individuals resilient and susceptible to the depressogenic effects of early life stress. Psychol Med 2013, 43(3):507-518. doi:10.1017/ 50033291712001390
125. Jin C, Qi R, Yin Y, Hu X, Duan L, Xu Q, Li L: Abnormalities in whole-brain functional connectivity observed in treatment-naive post-traumatic stress disorder patients following an earthquake. Psychol Med 2014, doi:10.1017/S003329171300250X.

126. Jovanovic T, Ressler KJ: How the neurocircuitry and genetics of fear inhibition may inform our understanding of PTSD. Am J Psychiatr 2011, 167(6):648-662. doi:10.1176/appi.ajp.2009.09071074.

127. Lee RJ, Hempel J, Tenharmsel A, Liu T, Mathe AA, Klock A: The neuroendocrinology of childhood trauma in personality disorder. Psychoneuroendocrinology 2012, 37(1):78-86. doi:10.1016/j. psyneuen.2011.05.006.

128. Mazza M, Tempesta D, Pino MC, Catalucci A, Gallucci M, Ferrara M: Regional cerebral changes and functional connectivity during the observation of negative emotional stimuli in subjects with post-traumatic stress disorder. Eur Arch Psychiatry Clin Neurosci 2013, 263(7):575-583. doi:10.1007/s00406-013-0394-3.

129. Rabinak CA, Angstadt M, Welsh RC, Kenndy AE, Lyubkin M, Martis B, Phan KL: Altered amygdala resting-state functional connectivity in post-traumatic stress disorder. Front Psychiatr 2011, 2:62. do:10.3389/fpsyt.2011.00062.

130. Sripada RK, King AP, Garfinkel SN, Wang X, Sripada CS, Welsh RC, Liberzon I: Altered resting-state amygdala functional connectivity in men with posttraumatic stress disorder. J Psychiatry Neurosci 2012, 37(4):241-249. doi:10.1503/jpn.110069.

131. Sripada RK, King AP, Welsh RC, Garfinkel SN, Wang X, Sripada CS, Liberzon I: Neural dysregulation in posttraumatic stress disorder: evidence for disrupted equilibrium between salience and default mode brain networks. Psychosom Med 2012, 74(9):904-911. doi:10.1097/ PSY.0b013e318273bf33.

132. Stevens JS, Jovanovic T, Fani N, Ely TD, Glover EM, Bradley B, Ressler KJ: Disrupted amygdala-prefrontal functional connectivity in civilian women with posttraumatic stress disorder. J Psychiatr Res 2013, 47(10):1469-1478. doi:10.1016/j.jpsychires.2013.05.031.

133. Yan X, Brown AD, Lazar M, Cressman VL, Henn-Haase C, Neylan TC, Marmar CR: Spontaneous brain activity in combat related PTSD. Neurosci Lett 2013, 547:1-5. doi:10.1016/j.neulet.2013.04.032.

134. Scherpiet S, Bruhl AB, Opialla S, Roth L, Jancke L, Herwig U: Altered emotion processing circuits during the anticipation of emotional stimul in women with borderline personality disorder. Eur Arch Psychiatry Clin Neurosci 2014, 264(1):45-60. doi:10.1007/s00406-013-0444-x.

135. Thomaes K, Dorrepaal E, Draijer N, de Ruiter MB, van Balkom AJ, Smit JH, Veltman DJ: Reduced anterior cingulate and orbitofrontal volumes in child abuse-related complex PTSD. J Clin Psychiatry 2010, 71(12):1636-1644. doi:10.4088/JCP.08m04754blu.

136. Thomaes K, Dorrepaal E, Draijer NP, de Ruiter MB, Elzinga BM, van Balkom AJ, Veltman DJ: Increased activation of the left hippocampus region in complex PTSD during encoding and recognition of emotional words: a pilot study. [Research Support, Non-U.S. Gov't]. Psychiatry Res 2009, 171(1):44-53. doi:10.1016/j.pscychresns.2008.03.003.

137. Thomaes K, Dorrepaal E, Draijer N, de Ruiter MB, Elzinga BM, Sjoerds Z Veltman DJ: Increased anterior cingulate cortex and hippocampus activation in complex PTSD during encoding of negative words. Soc Cognit Affect Neurosci 2013, 8(2):190-200. doi:10.1093/scan/nsr084.

138. Cardenas-Morales L, Fladung AK, Kammer T, Schmahl C, Plener PL, Connemann $B J$, Schonfeldt-Lecuona C: Exploring the affective component of pain perception during aversive stimulation in borderline personality disorder. Psychiatry Res 2011, 186(2-3):458-460. doi:10.1016/j.psychres.2010.07.050.

139. Liedl A, Knaevelsrud C: PTSD and chronic pain: development, maintenance and comorbidity-a review. Schmerz 2008, 22(6):644-651. doi:10.1007/s00482008-0714-0.

140. Morasco BJ, Lovejoy TI, Lu M, Turk DC, Lewis L, Dobscha SK: The relationship between PTSD and chronic pain: mediating role of coping strategies and depression. Pain 2013, 154(4):609-616. doi:10.1016/.jpain.2013.01.001.

141. Runnals JJ, Van Voorhees E, Robbins AT, Brancu M, Straits-Troster K, Beckham JC, Calhoun PS: Self-reported pain complaints among Afghanistan/Iraq Era men and women veterans with comorbid posttraumatic stress disorder and major depressive disorder. Pain Med 2014, doi:10.1111/pme.12208.

142. Elman I, Borsook D, Volkow ND: Pain and suicidality: insights from reward and addiction neuroscience. Prog Neurobiol 2013, 109:1-27. doi:10.1016/j. pneurobio.2013.06.003.

143. Niedtfeld I, Schulze L, Kirsch P, Herpertz SC, Bohus M, Schmahl C: Affect regulation and pain in borderline personality disorder: a possible link to 
the understanding of self-injury. [Research Support, Non-U.S. Gov't]. Biol Psychiatry 2010, 68(4):383-391. doi:10.1016/j.biopsych.2010.04.015.

144. Schmahl C, Meinzer M, Zeuch A, Fichter M, Cebulla M, Kleindienst N, Bohus M: Pain sensitivity is reduced in borderline personality disorder, but not in posttraumatic stress disorder and bulimia nervosa. World J Biol Psychiatry 2010, 11(2 Pt 2):364-371. doi:10.3109/15622970701849952.

145. Schaefer C, Enning F, Mueller JK, Bumb JM, Rohleder C, Odorfer TM, Leweke FM: Fatty acid ethanolamide levels are altered in borderline personality and complex posttraumatic stress disorders. Eur Arch Psychiatry Clin Neurosci 2014, doi:10.1007/s00406-013-0470-8.

146. Niedtfeld I, Kirsch P, Schulze L, Herpertz SC, Bohus M, Schmahl C: Functional connectivity of pain-mediated affect regulation in Borderline Personality Disorder. PLOS ONE 2012, 7(3):e33293. doi:10.1371/journal. pone.0033293.

147. Kluetsch RC, Schmahl C, Niedtfeld I, Densmore M, Calhoun VD, Daniels J, Lanius RA: Alterations in default mode network connectivity during pain processing in borderline personality disorder. Arch Gen Psychiatry 2012, 69(10):993-1002. doi:10.1001/archgenpsychiatry.2012.476.

148. Bluhm RL, Williamson PC, Osuch EA, Frewen PA, Stevens TK, Boksman K Lanius RA: Alterations in default network connectivity in posttraumatic stress disorder related to early-life trauma. J Psychiatry Neurosci 2009, 34(3):187-194.

149. Daniels JK, McFarlane AC, Bluhm RL, Moores KA, Clark CR, Shaw ME, Lanius RA: Switching between executive and default mode networks in posttraumatic stress disorder: alterations in functional connectivity. J Psychiatry Neurosci 2010, 35(4):258-266.

150. Porter KE, Pope EB, Mayer R, Rauch SA: PTSD and pain: exploring the impact of posttraumatic cognitions in veterans seeking treatment for PTSD. Pain Med 2013, 14(11):1797-1805. doi:10.1111/pme.12260.

151. Powers A, Fani N, Pallos A, Stevens J, Ressler KJ, Bradley B: Childhood abuse and the experience of pain in adulthood: the mediating effects of PTSD and emotion dysregulation on pain levels and pain-related functional impairment. Psychosomatics 2014, doi:10.1016/j.psym.2013.10.004.

152. Moeller-Bertram T, Keltner J, Strigo IA: Pain and post traumatic stress disorder - review of clinical and experimental evidence. Neuropharmacology 2012, 62 (2):586-597. doi:10.1016/..neuropharm.2011.04.028.

153. Geuze E, Westenberg HG, Jochims A, de Kloet CS, Bohus M, Vermetten E, Schmahl C: Altered pain processing in veterans with posttraumatic stress disorder. Arch Gen Psychiatry 2007, 64(1):76-85. doi:10.1001/archpsyc.64.1.76.

154. Strigo IA, Simmons AN, Matthews SC, Grimes EM, Allard CB, Reinhardt LE, Stein MB: Neural correlates of altered pain response in women with posttraumatic stress disorder from intimate partner violence. Biol Psychiatry 2010, 68(5):442-450. doi:10.1016/j.biopsych.2010.03.034.

155. Mickleborough MJ, Daniels JK, Coupland NJ, Kao R, Williamson PC, Lanius UF, Lanius RA: Effects of trauma-related cues on pain processing in posttraumatic stress disorder: an fMRI investigation. $J$ Psychiatry Neurosci 2011, 36(1):6-14. doi:10.1503/jpn.080188.

156. Taylor S, Asmundson GJ, Carleton RN: Simple versus complex PTSD: a cluster analytic investigation. [Comparative Study Research Support, Non-U.S. Gov't]. J Anxiety Disord 2006, 20(4):459-472. doi:10.1016/j.janxdis.2005.04.003.

157. Bryant RA: The complexity of complex PTSD. [Comment Editorial]. Am J Psychiatr 2010, 167(8):879-881. doi:10.1176/appi.ajp.2010.10040606.

158. van Dijke A, Ford JD, van der Hart $\mathrm{O}$, van Son M, van der Heijden P, Buhring M: Affect dysregulation in borderline personality disorder and somatoform disorder: differentiating under- and over-regulation. J Personal Disord 2010, 24(3):296-311. doi:10.1521/pedi.2010.24.3.296.

159. van Dijke A, van der Hart O, Ford JD, van Son M, van der Heijden P, Buhring M: Affect dysregulation and dissociation in borderline personality disorder and somatoform disorder: differentiating inhibitory and excitatory experiencing states. J Trauma Dissociation 2010, 11(4):424-443. doi:10.1080/15299732.2010.496140.

160. Arntz A, ten Haaf J: Social cognition in borderline personality disorder: evidence for dichotomous thinking but no evidence for less complex attributions. Behav Res Ther 2012, 50(11):707-718. doi:10.1016/j.brat.2012.07.002

161. Boen E, Westlye LT, Elvsashagen T, Hummelen B, Hol PK, Boye B, Malt UF: Regional cortical thinning may be a biological marker for borderline personality disorder. Acta Psychiatr Scand 2013, doi:10.1111/acps.12234.

162. Dinsdale N, Crespi BJ: The borderline empathy paradox: evidence and conceptual models for empathic enhancements in borderline personality disorder. J Personal Disord 2013, 27(2):172-195. doi:10.1521/ pedi.2013.27.2.172
163. Lazarus SA, Cheavens JS, Festa F, Zachary Rosenthal M: Interpersonal functioning in borderline personality disorder: a systematic review of behavioral and laboratory-based assessments. Clin Psychol Rev 2014, 34(3):193-205. doi:10.1016/j.cpr.2014.01.007.

164. Peter M, Schuurmans H, Vingerhoets AJ, Smeets G, Verkoeijen P, Arntz A: Borderline personality disorder and emotional intelligence. J Nerv Ment Dis 2013, 201(2):99-104. doi:10.1097/NMD.0b013e31827f64b0.

165. Preissler S, Dziobek I, Ritter K, Heekeren HR, Roepke S: Social cognition in borderline personality disorder: evidence for disturbed recognition of the emotions, thoughts, and intentions of others. Front Behav Neurosci 2010, 4:182. doi:10.3389/fnbeh.2010.00182.

166. Wingenfeld K, Kuehl LK, Janke K, Hinkelmann K, Dziobek I, Fleischer J, Roepke S: Enhanced emotional empathy after mineralocorticoid receptor stimulation in women with Borderline Personality Disorder and healthy somen. Neuropsychopharmacology 2014, doi:10.1038/npp.2014.36.

167. Depierro J, D'Andrea W, Pole N: Attention biases in female survivors of chronic interpersonal violence: relationship to trauma-related symptoms and physiology. Eur J Psychotraumatol 2013, 4. doi:10.3402/ejpt.v4i0.19135.

168. Flaks MK, Malta SM, Almeida PP, Bueno OF, Pupo MC, Andreoli SB, Bressan RA: Attentional and executive functions are differentially affected by post-traumatic stress disorder and trauma. J Psychiatr Res 2014, 48(1):32-39. doi:10.1016/j.jpsychires.2013.10.009.

169. Korzekwa MI, Dell PF, Links PS, Thabane L, Fougere P: Dissociation in borderline personality disorder: a detailed look. [Research Support, Non-U.S. Gov't]. J Trauma Dissociation 2009, 10(3):346-367. doi:10.1080/15299730902956838.

170. Hoerst M, Weber-Fahr W, Tunc-Skarka N, Ruf M, Bohus M, Schmahl C, Ende G: Correlation of glutamate levels in the anterior cingulate cortex with self-reported impulsivity in patients with borderline personality disorder and healthy controls. [Comparative Study Research Support, Non-U.S. Gov't]. Arch Gen Psychiatry 2010a, 67(9):946-954. doi:10.1001/ archgenpsychiatry.2010.93.

171. Irle E, Lange C, Weniger G, Sachsse U: Size abnormalities of the superior parietal cortices are related to dissociation in borderline personality disorder. Psychiatry Res 2007, 156(2):139-149. doi:10.1016/j. pscychresns.2007.01.007.

172. Ross CA, Ferrell L, Schroeder E: Co-occurrence of dissociative identity disorder and borderline personality disorder. [Research Support, Non-U. S. Gov't]. J Trauma Dissociation 2014, 15(1):79-90. doi:10.1080/ 15299732.2013.834861.

173. Roth S, Newman E, Pelcovitz D, vanderKolk B, Mandel FS: Complex PTSD in victims exposed to sexual and physical abuse: Results from the DSM-IV field trial for posttraumatic stress disorder. J Trauma Stress 1997, 10(4):539-555.

174. Zucker M, Spinazzola J, Blaustein M, van der Kolk BA: Dissociative symptomatology in posttraumatic stress disorder and disorders of extreme stress. J Trauma Dissociation 2006, 7(1):19-31.

175. Dorahy MJ, Corry M, Shannon M, Webb K, McDermott B, Ryan M, Dyer KF: Complex trauma and intimate relationships: the impact of shame, guilt and dissociation. J Affect Disord 2013, 147(1-3):72-79. doi:10.1016/j. jad.2012.10.010.

176. Putnam FW: Taking the measure of dissociation. J Trauma Dissociation 2009, 10(3):233-236. doi:10.1080/15299730902956564

177. Brand BL, Lanius R, Vermetten E, Loewenstein RJ, Spiegel D: Where are we going? An update on assessment, treatment, and neurobiological research in dissociative disorders as we move toward the DSM-5. $J$ Trauma Dissociation 2012, 13(1):9-31. doi:10.1080/15299732.2011.620687.

178. Spiegel D, Loewenstein RJ, Lewis-Fernandez R, Sar V, Simeon D, Vermetten E, Dell PF: Dissociative disorders in DSM-5. [Review]. Depress Anxiety 2011 , 28(9):824-852. doi:10.1002/da.20874.

179. Ford JD: Dissociation in Complex Postttraumatic Stress Disorder or Disorders of Extreme Stress Not Otherwise Specified (DESNOS). In Dissociation and the Dissociative Disorders: DSM-V and beyond. Edited by Dell PF, O'Neill JA. New York: Routledge; 2009:471-483.

180. Carpenter RW, Trull TJ: Components of emotion dysregulation in borderline personality disorder: a review. [Review]. Curr Psychiatr Rep 2013, 15(1):335. doi:10.1007/s11920-012-0335-2.

181. Gratz KL, Rosenthal MZ, Tull MT, Lejuez CW, Gunderson JG: An experimental investigation of emotional reactivity and delayed emotional recovery in borderline personality disorder: the role of shame. Compr Psychiatry 2010, 51(3):275-285. doi:10.1016/j.comppsych.2009.08.005.

182. Carvalho Fernando S, Beblo T, Schlosser N, Terfehr K, Otte C, Lowe B, Wingenfeld $K$ : The impact of self-reported childhood trauma on emotion 
regulation in borderline personality disorder and major depression. J Trauma Dissociation 2014, doi:10.1080/15299732.2013.863262.

183. Gratz KL, Tull MT, Baruch DE, Bornovalova MA, Lejuez CW: Factors associated with co-occurring borderline personality disorder among inner-city substance users: the roles of childhood maltreatment, negative affect intensity/reactivity, and emotion dysregulation. Compr Psychiatry 2008, 49(6):603-615. doi:10.1016/j.comppsych.2008.04.005.

184. MK Suvak, CT Sege, DM Sloan, MT Shea, S Yen, BT Litz: Emotional processing in borderline personality disorder. Personality Disorders: Theory, Research, and Treatment 2012, 3(3):273-282. http://scholar.google.com.au/ citations?view_op=view_citation\&hl=en\&user=z6lcOROAAAAJ\& cstart=20\&citation for $\_$view $=$z6lcOROAAAAJ:M3ejUd6NZC8C

185. Bardeen JR, Dixon-Gordon KL, Tull MT, Lyons JA, Gratz KL: An investigation of the relationship between borderline personality disorder and cocaine-related attentional bias following trauma cue exposure: the moderating role of gender. Compr Psychiatry 2014, 55(1):113-122. doi:10.1016/j.comppsych.2013.08.011.

186. Gratz KL, Tull MT, Matusiewicz AM, Breetz AA, Lejuez CW: Multimodal examination of emotion regulation difficulties as a function of co-occurring avoidant personality disorder among women with borderline personality disorder. Pers Assess 2013, 4(4):304-314. doi:10.1037/per0000020

187. Gratz KL, Tull MT, Reynolds EK, Bagge CL, Latzman RD, Daughters SB, Lejuez CW: Extending extant models of the pathogenesis of borderline personality disorder to childhood borderline personality symptoms: the roles of affective dysfunction, disinhibition, and self- and emotion-regulation deficits. Dev Psychopathol 2009, 21(4):1263-1291. doi:10.1017/S0954579409990150.

188. Gratz KL, Latzman RD, Tull MT, Reynolds EK, Lejuez CW: Exploring the association between emotional abuse and childhood borderline personality features: the moderating role of personality traits. BehaviorTherapy 2011, 42(3):493-508. doi:10.1016/j.beth.2010.11.003.

189. Fossati A, Gratz KL, Maffei C, Borroni S: Emotion dysregulation and impulsivity additively predict borderline personality disorder features in Italian nonclinical adolescents. Personal Ment Health 2013, 7(4):320-333. doi:10.1002/pmh.1229.

190. Aldao A, Nolen-Hoeksema S, Schweizer S: Emotion-regulation strategies across psychopathology: a meta-analytic review. [Meta-Analysis]. Clin Psychol Rev 2010, 30(2):217-237. doi:10.1016/..cpr.2009.11.004.

191. Kim J, Cicchetti D: Longitudinal pathways linking child maltreatment, emotion regulation, peer relations, and psychopathology. J Child Psychol Psychiatry 2010, 51(6):706-716. doi:10.1111/j.1469-7610.2009.02202.x.

192. Waller E, Scheidt CE: Somatoform disorders as disorders of affect regulation: a study comparing the TAS-20 with non-self-report measures of alexithymia. J Psychosom Res 2004, 57(3):239-247. doi:10.1016/S00223999(03)00613-5.

193. Lyons-Ruth K, Choi-Kain L, Pechtel P, Bertha E, Gunderson J: Perceived parental protection and cortisol responses among young females with borderline personality disorder and controls. Psychiatry Res 2011, 189(3):426-432. doi:10.1016/j.psychres.2011.07.038.

194. Cole PM, Llera SJ, Pemberton CK: Emotional instability, poor emotional awareness, and the development of borderline personality. Dev Psychopathol 2009, 21(4):1293-1310. doi:10.1017/S0954579409990162.

195. Cicchetti D, Toth SL: A developmental psychopathology perspective on child abuse and neglect. J Am Acad Child Adolesc Psychiatry 1995, 34(5):541-565. doi:10.1097/00004583-199505000-00008.

196. Kim-Spoon J, Cicchetti D, Rogosch FA: A longitudinal study of emotion regulation, emotion lability-negativity, and internalizing symptomatology in maltreated and nonmaltreated children. Child Dev 2013, 84(2):512-527. doi:10.1111/j.1467-8624.2012.01857.x

197. Schore AN: Attachment and the regulation of the right brain. Am J Bioeth 2000, 2(1):23-47. doi:10.1080/146167300361309.

198. Agrawal HR, Gunderson J, Holmes BM, Lyons-Ruth K: Attachment studies with borderline patients: a review. [Review]. Harv Rev Psychiatry 2004, 12(2):94-104. doi:10.1080/10673220490447218.

199. Newman LK, Stevenson CS, Bergman LR, Boyce P: Borderline personality disorder, mother-infant interaction and parenting perceptions: preliminary findings. Aust N Z J Psychiatry 2007, 41(7):598-605. doi:10.1080/00048670701392833.

200. Hobson RP, Patrick MP, Hobson JA, Crandell L, Bronfman E, Lyons-Ruth K: How mothers with borderline personality disorder relate to their year-old infants. Br J Psychiatry 2009, 195(4):325-330. doi:10.1192/bjp.bp.108.060624.

201. Van Dijke A, Ford JD, Frank L, Van Son M, Van der Hart O: Association of childhood trauma-by-primary-caregiver and affect dysregulation with borderline personality disorder symptoms in adulthood. Psychol Trauma 2013, 5(3):217-224

202. Weinberg I, Ronningstam E, Goldblatt MJ, Schechter M, Maltsberger JT: Common factors in empirically supported treatments of borderline personality disorder. Curr Psychiatr Rep 2011, 13(1):60-68. doi:10.1007/ s11920-010-0167-X

203. Belford B, Kaehler LA, Birrell P: Relational health as a mediator between betrayal trauma and borderline personality disorder. J Trauma Dissociation 2012, 13(2):244-257. doi:10.1080/15299732.2012.642750.

204. Courtois CA, Ford JD: Treating Complex Trauma: A Sequenced Relationship-Based Approach. New York: Guilford; 2013.

205. Ford JD, Courtois CA (Eds): Treating complex traumatic stress disorders in children and adolescents: Scientific foundations and therapeutic models. New York: Guilford; 2013.

206. Ford JD: Neurobiological and Developmental Research: Clinical Implications. In Treating Complex Traumatic Stress Disorders : an Evidence-Based Guide. Edited by Courtois CA, Ford JD. New York: Guilford Press; 2009:31-58.

207. Robertson CD, Kimbrel NA, Nelson-Gray RO: The Invalidating Childhood Environment Scale (ICES): psychometric properties and relationship to borderline personality symptomatology. J Personal Disord 2013, 27(3):402-410. doi:10.1521/pedi_2012_26_062.

208. Herman JL: Foreword. In Treating traumatic stress disorders: an evidence-based guide (pp. xii-xvii). Edited by Courtois CA, Ford JD. New York: Guilford Press; 2009

209. Neacsiu AD, Lungu A, Harned MS, Rizvi SL, Linehan MM: Impact of dialectical behavior therapy versus community treatment by experts on emotional experience, expression, and acceptance in borderline personality disorder. Behav Res Ther 2014, 53:47-54. doi:10.1016/j.brat.2013.12.004.

210. Harned MS, Korslund KE, Linehan M: A pilot randomized controlled trial of Dialectical Behavior Therapy with and without the Dialectical Behavior Therapy Prolonged Exposure protocol for suicidal and self-injuring women with borderline personality disorder and PTSD. Behav Res Ther 2014, 55:7-17.

211. Bohus M, Dyer AS, Priebe K, Kruger A, Kleindienst N, Schmahl C, Steil R: Dialectical behaviour therapy for post-traumatic stress disorder after childhood sexual abuse in patients with and without borderline personality disorder: a randomised controlled trial. Psychother Psychosom 2013, 82(4):221-233. doi:10.1159/000348451.

212. Cloitre M, Koenen KC, Cohen LR, Han H: Skills training in affective and interpersonal regulation followed by exposure: a phase-based treatment for PTSD related to childhood abuse. J Consult Clin Psychol 2002, 70(5):1067-1074

213. Cloitre M, Petkova E, Wang J, Lu Lassell F: An examination of the influence of a sequential treatment on the course and impact of dissociation among women with PTSD related to childhood abuse. Depress Anxiety 2012, 29(8):709-717. doi:10.1002/da.21920.

214. Cloitre M, Stovall-McClough KC, Nooner K, Zorbas P, Cherry S, Jackson CL, Petkova E: Treatment for PTSD related to childhood abuse: a randomized controlled trial. Am J Psychiatr 2010, 167(8):915-924. doi:10.1176/appi. ajp.2010.09081247

215. Ford JD, Steinberg KL, Zhang W: A randomized clinical trial comparing affect regulation and social problem-solving psychotherapies for mothers with victimization-related PTSD. Behav Ther 2011, 42(4):560-578. doi:10.1016/j.beth.2010.12.005.

216. Frisman LK, Ford JD, Lin H, Mallon S, Chang R: Outcomes of trauma treatment using the TARGET model. Journal of Groups in Addiction and Recovery 2008, 3:285-303.

217. Ford JD, Steinberg KL, Hawke J, Levine J, Zhang W: Randomized trial comparison of emotion regulation and relational psychotherapies for PTSD with girls involved in delinquency. J Clin Child Adolesc Psychol 2012 41(1):27-37. doi:10.1080/15374416.2012.632343.

218. Insel T, Cuthbert B, Garvey M, Heinssen R, Pine DS, Quinn K, Wang P: Research domain criteria (RDoC): toward a new classification framework for research on mental disorders. Am J Psychiatr 2010, 167(7):748-751. doi:10.1176/appi.ajp.2010.09091379.

219. Lei H, Nahum-Shani I, Lynch K, Oslin D, Murphy SA: A "SMART" design for building individualized treatment sequences. Annu Rev Clin Psychol 2012 8:21-48. doi:10.1146/annurev-clinpsy-032511-143152.

doi:10.1186/2051-6673-1-9

Cite this article as: Ford and Courtois: Complex PTSD, affect dysregulation, and borderline personality disorder. Borderline Personality Disorder and Emotion Dysregulation 2014 1:9. 